\title{
Para usar en la cocina. Adquisición, producción y uso de artefactos líticos en la Estructura 1 de Cardonal (Valle del Cajón, Catamarca)
}

\author{
Natalia Sentinelli" y M. Cristina Scattolin **
}

\section{Resumen}

En este trabajo se propone la reconstrucción de las actividades de talla lítica llevadas a cabo en la Estructura 1 del Núcleo 1 del sitio arqueológico Cardonal en el valle del Cajón (Catamarca) a comienzos de la Era Cristiana. El estudio de este recinto, interpretado como la cocina de la casa, permitió analizar procesos tecnológicos microescalares para considerar el flujo de acciones técnicas incluidas en la realidad cotidiana de una vivienda. Aquí se evalúa la elección de recursos líticos por parte de los residentes en la casa, se estudia la variabilidad artefactual en el conjunto lítico recuperado y se identifican las actividades tecnológicas líticas ocurridas en esta habitación. La metodología aplicada y los resultados obtenidos permitieron determinar la diversidad de rocas utilizadas, como también reconstruir una extensa gama de actividades de producción lítica. Se entiende a la tecnología lítica como inmersa en las prácticas cotidianas en el marco de redes de relaciones que comprendían no sólo a otros habitantes de Cardonal, sino también a personas y paisajes distantes.

To be used in the kitchen. Acquisition, production and use of lithic artifacts in Structure 1 of Cardonal (Cajón Valley, Catamarca)

\begin{abstract}
This paper presents the reconstruction of lithic knapping activities carried out within Structure 1 of Compound 1 in the Cardonal archaeological site (Cajón Valley, Catamarca) at the beginning of the Christian Era. The study of this structure, interpreted as the house kitchen, allowed us to analyze microscale technological processes, and so address the sum of technical actions that constituted daily life within the house. We evaluated the selection of lithic resources chosen by the inhabitants of the house and studied artifact variability within the lithic assemblage recovered, thereby identifying the lithic technological activities that occurred in the room. The methodology employed

and the results obtained allowed us to determine the diversity of rocks used, as well as to
\end{abstract}

* Escuela de Arqueología, Universidad Nacional de Catamarca (UNCa) Maximo Victoria s/n (CP K4751XAK) San Fernando del Valle de Catamarca, Catamarca, Argentina. E-mail: nataliasentinelli@gmail.com ** Instituto de las Culturas (IDECU), Museo Etnográfico “J. B. Ambrosetti”, Facultad de Filosofía y Letras, Universidad de Buenos Aires (UBA) - CONICET. Moreno 350 (CP C1091AAH) Ciudad Autónoma de Buenos Aires, Argentina. E-mail: cscattolin@gmail.com
}

Recibido:

13 de marzo de 2018

Aceptado:

30 de julio de 2018

\section{Palabras clave}

Tecnología Herramientas líticas

Talla lítica

Actividades domésticas

Materias primas

\section{Keywords}

Technology Stone tools Lithic knapping Domestic activities Raw materials 
reconstruct a wide range of lithic production activities. We focused on lithic technology embedded in everyday practices within network frameworks that included not only other Cardonal residents, but also more distant people and landscapes.

\section{Introducción}

Las prácticas técnicas entretejen múltiples aspectos de la vida humana en una red multidimensional y son parte estructurante de las actividades domésticas en las que las personas cotidianamente crean y recrean su mundo material y social, de modo que se transforman mutuamente en esa relación (Bourdieu, 1980; Dobres, 1999; Ingold, 1990, 2000; Pfaffenberger, 1992, 1999). En este sentido, las prácticas tecnológicas pueden ser definidas como formas de actuar institucionalizadas para lograr múltiples fines, entre ellos, la producción de herramientas, la expresión de identidades, el establecimiento y mantenimiento de relaciones sociales y la reproducción social del grupo.

Con estas ideas en mente, el objetivo de este trabajo es la reconstrucción de las prácticas tecnológicas relacionadas con la producción lítica en la Estructura 1 (E1) del Núcleo 1 de Cardonal (valle del Cajón, Catamarca) (Figura 1) y su vinculación con otras tareas domésticas, principalmente culinarias. La posibilidad de estudiar una habitación particular - la cocina de una vivienda aldeana- permite analizar en detalle procesos tecnológicos a nivel microescalar, no sólo como nivel físico de análisis sino también como escala en la cual se observa el flujo de prácticas que conforman la realidad cotidiana de los residentes para posibilitar luego una comprensión de los procesos tecnológicos y sociales más amplios o macroescalares.

El Núcleo 1 de la aldea de Cardonal está compuesto por cinco habitaciones adosadas entre sí; tres de ellas (E1, E2 y E4) se comunican con un recinto (E3), probablemente semicerrado, que desemboca en un espacio común o "portal" abierto al exterior (Figura 1), al cual desemboca también un patio amplio (E5).

La E1 de Cardonal tiene como rasgo sobresaliente una estructura de combustión compuesta por tres grandes piedras unidas por cordones de arcilla compacta. La matriz sedimentaria del nivel de ocupación, muy oscura y grasienta, evidencia que el tizne cubría el recinto y que éste había estado cubierto de hollín durante su historia ocupacional. Se hallaron fragmentos de huesos asignables a camélidos con marcas de procesamiento primario o secundario (Izeta, 2007), fragmentos de vasijas cerámicas, morteros y manos de piedra, restos de vegetales carbonizados y los artefactos de piedra tallada que se tratan en el presente artículo. Este nivel fue fechado, sobre muestras de carbón, en $1841 \pm 35$ años AP (AA82262) y $1870 \pm 40 \mathrm{cal}$ AP (cal 80-330 DC al 95\%, en Gero, 2015, p. 323, sin mención de laboratorio).

Sobre la roca de base había varios pozos, uno con cenizas blancas y otro que incluía sedimento oscuro (Figura 1), los cuales pudieron haber funcionado como puntos asistentes de calor y braseros, como cubetas para la limpieza de cenizas o para la guarda de utensilios. En otro sector se pudo determinar un lugar de molienda compuesto por una conana, 19 artefactos de piedra pulida, semillas, vasijas cerámicas y restos macrobotánicos de maíz (Zea mays), poroto (Phaseolus vulgaris var. vulgaris y P. $v$. var. aborigineus), chañar (Geoffroea decorticans) y otros no identificados (Calo, 2010).

El sistema de rasgos evidencia una estructura multifuncional en la que debieron desarrollarse varias tareas configurando una escenografía propia de una cocina: cocción de alimentos, preparación de bebidas, calefacción, mantenimiento de líquidos 

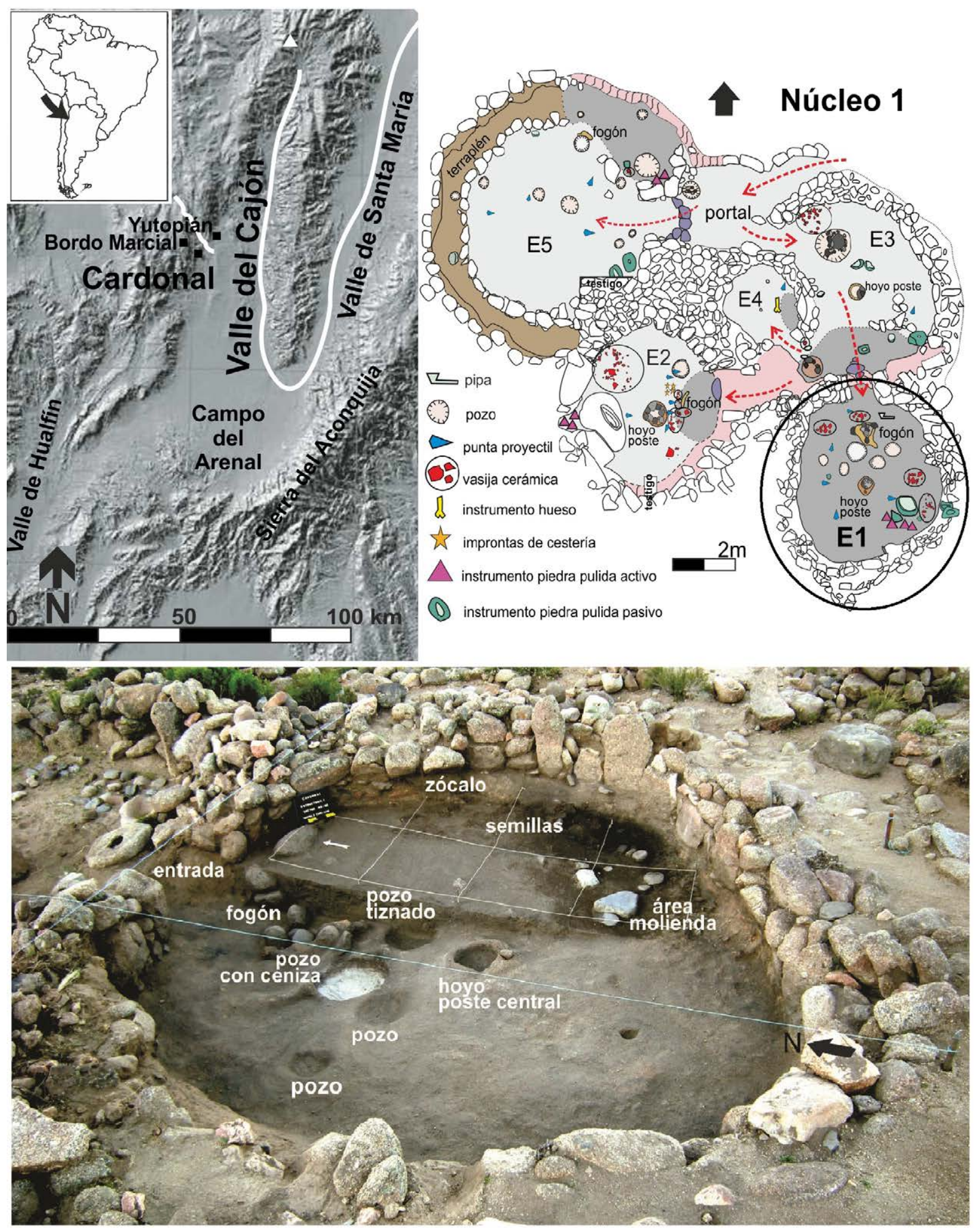

Figura 1. Localización de la aldea de Cardonal, plano del Núcleo 1 y vista de la cocina (estructura E1).

calientes y/o producción de brasas (Bugliani, Calo y Scattolin, 2010). Así, reconstruir las actividades involucradas en la producción y uso de artefactos líticos hace necesario olvidarse de las "premisas generalizadas sobre lo que ocurre en y alrededor de la casa" 
(Tringham, 1999, p. 107) y concebir estas escenografías como espacios donde confluían distintas personas con diversas tareas en diferentes momentos de su vida cotidiana.

En cuanto a los antecedentes relacionados con el estudio de la producción lítica en la zona, Sentinelli y Toselli (2013) han comenzado a indagar sobre la base regional de recursos líticos. Cabe destacar que en dicha ocasión el análisis involucró al conjunto lítico analizado en este trabajo a partir de la identificación de las materias primas presentes en la E1 mediante estudios realizados a ojo desnudo y con microscopio (Sentinelli y Toselli, 2013).

De esta forma, en base a las observaciones macroscópicas, se pudo identificar en la E1 la presencia de cuarzo, calcedonia, toba dacítica, rocas metamórficas foliadas, tres variedades de obsidianas, una roca cuarcítica no determinada de color claro y grano muy fino y 14 agrupaciones preliminares de vulcanitas no vítreas. Los análisis petrográficos permitieron, entre otras rectificaciones y corroboraciones, determinar que las diferencias fundamentales se relacionaban con la presencia de dos tipos mayores de rocas, basaltos y andesitas, y luego con la presencia de variedades dentro de estos dos grupos. Además, la petrografía determinó que la roca cuarcítica color claro se trata de una metacuarcita (Sentinelli y Toselli, 2013).

Con estos resultados, la litoteca de la Estructura 1 quedó compuesta por: (a) vulcanitas, que comprenden dos variedades de basaltos (Bs1 y Bs2), cuatro variedades de andesitas (An1, An2, AnS y AnC), una vulcanita fina (VcF), una vulcanita con pequeños fenocristales $(\mathrm{VcP})$ y un pequeño número de vulcanitas no diferenciadas $(\mathrm{VcN})$; (b) rocas cuarcíticas, que comprenden el cuarzo $(\mathrm{Cz})$, la calcedonia $(\mathrm{Cal})$ y la metacuarcita $(\mathrm{Mcc})$; (c) tres variedades de obsidianas, que corresponden a las fuentes Ona-Las Cuevas (Ob1), Cueros de Purulla (Ob2) y Laguna Cavi (Ob3); (d) un grupo de rocas metamórficas foliadas (Fi); y (e) un reducido número de materias primas no diferenciadas (MpN) (Sentinelli y Toselli, 2013).

A partir de una serie de inferencias acerca de la disponibilidad potencial de cada una de las rocas y sobre la base de la información geológica de la zona se determinó la presencia de rocas de disponibilidad local (inmediatas, mediatas cercanas, mediatas lejanas, e indiferenciadas) y no local (Sentinelli y Toselli, 2013). Entre las rocas de disponibilidad local se encuentra, en primer lugar, el cuarzo, la única materia prima inmediata, presente en la formación geológica de Chango Real que aflora a pocos metros del sitio. Las materias primas mediatas cercanas son las andesitas en la formación geológica Negro Caranchi, la toba dacítica en la formación geológica Laguna Blanca y la metacuarcita y las rocas metamórficas foliadas en la formación precámbrica Loma Corral. Finalmente, las únicas materias primas locales mediatas lejanas serían los basaltos, que afloran en la formación Los Rastrojitos, en las zonas de Peña Alta, en Peñas Azules y en Río Blanco. Las restantes variedades de vulcanitas y la calcedonia se consideran rocas de probable origen local pero deben ser clasificadas como indiferenciadas por falta de datos.

En cuanto a las materias primas no locales presentes en Cardonal, registramos tres variedades de obsidianas, todas con fuentes localizadas en la Puna catamarqueña: Ona-Las Cuevas (160 km de Cardonal), Cueros de Purulla (130 km) y Laguna Cavi $(100 \mathrm{~km})$ (Sentinelli y Toselli, 2013).

\section{Metodología}

En consideración de la gran cantidad de materiales líticos recuperados en la E1, se analizó una muestra del conjunto artefactual $(\mathrm{n}=1.617)$ seleccionada mediante un muestreo sistemático dirigido sobre la base de las unidades de excavación ${ }^{1}$ (Sentinelli, 2012). Dicho muestreo procedió a partir de una tabla en las que se ubicaron todas las unidades excavadas organizadas a partir del nivel estratigráfico - filas - y la cuadrícula - columnas-. Se comenzó seleccionando desde la cuadrícula A-nivel 6 y se continuó
1. Cada unidad de excavación se constituye por la intersección de nivel y cuadricula, por ejemplo, unidad C516: Cuadrícula A, Nivel 3. 
tomando el nivel superior de cada cuadrícula contigua, hasta que todas las cuadrículas y todos los niveles estuvieran representados. Luego se procedió de la misma manera en dos corridas más, con una separación de un nivel (uno hacia arriba y uno hacia abajo). Esta selección generó una muestra del 43,33\% ( $\mathrm{n}=13$ unidades) de las unidades de excavación recuperadas en la excavación del año 2008.

Apuntando a la comprensión del proceso de producción lítica, recurrimos a un enfoque analítico de tipo tecnológico. El conjunto fue segmentado en clases tipológicas: desechos de talla, núcleos e instrumentos. La clase instrumentos comprendió artefactos formatizados, artefactos con filos, puntas o superficies con rastros complementarios y litos no diferenciados modificados por uso. Entre estos últimos, en este trabajo no se incluyeron los artefactos para molienda, que fueran estudiados anteriormente (Calo, 2010; Calo, Bugliani y Scattolin, 2012). El análisis técnico-morfológico se basó fundamentalmente en las propuestas de Aschero $(1975,1983)$, Bellelli, Guraieb y García (1985-87), Sullivan y Rozen (1985), Aschero y Hocsman (2004), entre otros.

En el caso de los desechos de talla, las variables analizadas fueron: materia prima, estado de fragmentación, origen de las extracciones y tipo de lasca, porcentaje de corteza, tamaño relativo, grosor relativo, módulo de longitud/anchura y regularización del frente de extracción. Para las variables origen de las extracciones y tipo de lasca no se tomaron en cuenta los productos indiferenciados (el subgrupo quedó conformado por productos bipolares enteros y fracturados y lascas enteras y fracturadas, con y sin talón, $\mathrm{n}=1.496)$. El análisis de núcleos incluyó las variables: materia prima, estado de fragmentación, forma base, forma del núcleo y cantidad y estado de la/s plataforma/s. Para los instrumentos, las variables analizadas fueron: materia prima, estado de fragmentación, tamaño relativo, grosor relativo, módulo de longitud/anchura, forma base, clase técnica, grupo/s tipológico/s presente/s, situación de los lascados y serie técnica. Cabe mencionar que en el caso de las variables dimensionales solo se consideraron las piezas enteras, tanto en los desechos de talla como en los núcleos e instrumentos.

\section{Resultados}

\section{Frecuencias de materias primas}

La variabilidad en las frecuencias de aparición de los distintos tipos de roca dentro del conjunto permite comenzar a entender el aprovechamiento de estos recursos líticos de disponibilidad diferencial (Tabla 1). Al respecto, las rocas locales comprenden el 97,77\% del conjunto. Casi tres cuartas partes de ellas $(73,75 \%, n=1.581)$ corresponden a las materias primas locales mediatas (andesitas, basaltos, vulcanitas, toba dacítica, metacuarcita y rocas metamórficas foliadas). Además, dentro de las materias primas mediatas predominan marcadamente aquellas mediatas lejanas, es decir, los basaltos (Bs1 y Bs2) $(63,86 \%, \mathrm{n}=1034)$. Esta predominancia viene dada fundamentalmente por la recurrencia del basalto variedad 1 (Bs1), que comprende más de la mitad de la muestra de artefactos $(59,17 \%, \mathrm{n}=958)$.

El cuarzo, la única roca de disponibilidad inmediata, comprende el 20,82\% ( $\mathrm{n}=337)$ de la muestra, siendo la segunda materia prima más utilizada en el conjunto a pesar de su baja calidad para la talla.

Luego, continúan en representación cuatro variedades de rocas volcánicas (Bs2, AnS, An2, $\mathrm{VcN}$ ) y la metacuarcita, aunque ninguna supera el 5\%. Finalmente, el resto de las materias primas ( $\mathrm{ToD}, \mathrm{VcP}, \mathrm{VcF}, \mathrm{Anl}, \mathrm{AnC}$ y Cal) comprenden en conjunto sólo el 2,3\% de la muestra.

En cuanto a las materias primas no locales, las tres variedades de obsidianas comprenden en conjunto el $2,1 \%$ de la muestra. 


\begin{tabular}{|c|c|c|c|c|c|c|c|c|c|}
\hline \multirow{2}{*}{\multicolumn{2}{|c|}{ Materia prima }} & \multicolumn{2}{|c|}{ Desechos } & \multicolumn{2}{|c|}{ Instrumentos } & \multicolumn{2}{|c|}{ Núcleos } & \multicolumn{2}{|c|}{ Total } \\
\hline & & $\mathrm{n}$ & $\%$ & $\mathrm{n}$ & $\%$ & $\mathrm{n}$ & $\%$ & $\mathrm{n}$ & $\%$ \\
\hline Cuarzo & Inmediata & 325 & $21,05 \%$ & 12 & $16,67 \%$ & o & ०,0०\% & 337 & $20,82 \%$ \\
\hline Andesita silicificada & \multirow{7}{*}{$\begin{array}{l}\text { Mediatas } \\
\text { cercanas }\end{array}$} & 41 & $2,66 \%$ & o & $0,00 \%$ & o & ०,००\% & 41 & $2,53 \%$ \\
\hline Andesita variedad 2 & & 37 & $2,40 \%$ & o & $0,00 \%$ & o & o,o०\% & 37 & $2,29 \%$ \\
\hline Andesita variedad 1 & & 7 & $0,45 \%$ & 1 & $1,39 \%$ & o & ०,0०\% & 8 & $0,49 \%$ \\
\hline Andesita cuarzosa & & 2 & $0,13 \%$ & o & $0,00 \%$ & o & o,o०\% & 2 & $0,12 \%$ \\
\hline Metacuarcita & & 35 & $2,27 \%$ & 1 & $1,39 \%$ & o & $0,00 \%$ & 36 & $2,22 \%$ \\
\hline Metamórficas foliadas & & & & 6 & $8,33 \%$ & o & ०,००\% & 6 & $0,37 \%$ \\
\hline Toba dacítica & & 1 & $0,06 \%$ & 1 & $1,39 \%$ & o & ०,००\% & 2 & $0,12 \%$ \\
\hline Basalto variedad 1 & \multirow{2}{*}{$\begin{array}{l}\text { Mediatas } \\
\text { lejanas }\end{array}$} & 910 & $58,94 \%$ & 47 & $65,28 \%$ & 1 & $100,00 \%$ & 958 & $59,17 \%$ \\
\hline Basalto variedad 2 & & 76 & $4,92 \%$ & 0 & o,o०\% & o & o,o०\% & 76 & $4,69 \%$ \\
\hline Vulc. no diferenciadas & \multirow{4}{*}{$\begin{array}{l}\text { Locales } \\
\text { indiferenc. }\end{array}$} & 53 & $3,43 \%$ & o & o,o०\% & o & $0,00 \%$ & 53 & $3,27 \%$ \\
\hline Vulcanita VcP & & 23 & $1,49 \%$ & o & ०,००\% & o & ০,००\% & 23 & $1,42 \%$ \\
\hline Calcedonia & & 1 & $0,06 \%$ & o & $0,00 \%$ & o & $0,00 \%$ & 1 & $0,06 \%$ \\
\hline Vulcanita VcF & & 1 & $0,06 \%$ & o & ०,००\% & o & ০,००\% & 1 & $0,06 \%$ \\
\hline Obs. Ona-Las Cuevas & \multirow{3}{*}{ No locales } & 25 & $1,62 \%$ & 2 & $2,78 \%$ & o & o,००\% & 27 & $1,67 \%$ \\
\hline Obs. Laguna Cavi & & 3 & $0,19 \%$ & 1 & $1,39 \%$ & o & ०,००\% & 4 & $0,25 \%$ \\
\hline Obs. Cueros de Purulla & & 2 & $0,13 \%$ & 1 & $1,39 \%$ & o & ०,००\% & 3 & $0,19 \%$ \\
\hline $\begin{array}{l}\text { Materias primas no } \\
\text { diferenciadas }\end{array}$ & $\begin{array}{c}\text { No } \\
\text { diferenc. }\end{array}$ & 2 & $0,13 \%$ & o & o,oo\% & o & ०,००\% & 2 & $0,12 \%$ \\
\hline Totales & & 1.544 & $100 \%$ & 72 & $100 \%$ & 1 & $100 \%$ & 1.617 & $100 \%$ \\
\hline
\end{tabular}

Tabla 1. Comparación de frecuencias absolutas y porcentuales de materias primas para las distintas clases tipológicas $(n=1.617)$. Referencias: Vulc.: vulcanitas; VcP: vulcanita con pequeños fenocristales; VcF: vulcanita fina; Obs.: obsidiana.

2. Se detallan aquí solo algunas de las variables analizadas; para el estudio completo de los datos ver Sentinelli (2012, 2016).

\section{Los grupos de artefactos}

La muestra está compuesta por 1.544 desechos de talla, 72 instrumentos y un núcleo. Los resultados de los análisis técnico-morfológicos sobre cada una de estas clases tipológicas permiten comenzar a reconstruir la dinámica del proceso de producción lítica y las prácticas tecnológicas en $E 1^{2}$.

\section{Desechos de talla}

La distribución de materias primas en la clase tipológica de los desechos de talla es la que marca las tendencias generales del conjunto: hay una preponderancia muy marcada de las materias primas locales, entre las cuales las rocas de disponibilidad mediata tienen representación mayoritaria, seguidas por las materias primas de disponibilidad mediata lejana. Particularmente, predomina el basalto Bs1, seguido por el cuarzo y para el resto de las materias primas los porcentajes son mucho menores. Cabe destacar que no se registraron desechos de talla de rocas metamórficas foliadas, las cuales sí se presentan en los instrumentos (Tabla 1).

Las lascas son los desechos predominantes $(\mathrm{n}=1.483)$, y se registraron productos bipolares $(n=13)$ y desechos indiferenciados $(n=48)$. Las lascas muestran un porcentaje relativamente alto de fragmentación $(60,15 \%)$, mientras que en los bipolares este índice es muy bajo (15,38\%) (Tabla 2). 


\begin{tabular}{|c|c|c|c|c|c|c|c|c|c|c|c|c|c|c|}
\hline \multirow{3}{*}{ Materias primas } & \multicolumn{14}{|c|}{ Origen de las extracciones } \\
\hline & \multicolumn{2}{|c|}{$\begin{array}{c}\text { Prod. } \\
\text { bipolares }\end{array}$} & \multicolumn{2}{|c|}{$\begin{array}{l}\text { Lascas } \\
\text { externas }\end{array}$} & \multicolumn{2}{|c|}{$\begin{array}{c}\text { Lascas } \\
\text { internas }\end{array}$} & \multicolumn{2}{|c|}{$\begin{array}{c}\text { Reactivación } \\
\text { de filos }\end{array}$} & \multicolumn{2}{|c|}{$\begin{array}{c}\text { Reactivación } \\
\text { de núcleos }\end{array}$} & \multicolumn{2}{|c|}{$\begin{array}{c}\text { Lascas } \\
\text { no diferenc. }\end{array}$} & \multicolumn{2}{|c|}{ Totales } \\
\hline & $n$ & $\%$ & $\mathrm{n}$ & $\%$ & $\mathrm{n}$ & $\%$ & $\mathrm{n}$ & $\%$ & $\mathrm{n}$ & $\%$ & $\mathrm{n}$ & $\%$ & $\mathrm{n}$ & $\%$ \\
\hline Andesita 1 & o & $0,00 \%$ & 1 & $14,29 \%$ & 6 & $85,71 \%$ & o & $0,00 \%$ & o & $0,00 \%$ & o & $0,00 \%$ & 7 & $100 \%$ \\
\hline Andesita 2 & $\mathrm{o}$ & $0,00 \%$ & 3 & $8,11 \%$ & 31 & $83,78 \%$ & o & $0,00 \%$ & o & $0,00 \%$ & 3 & $8,11 \%$ & 37 & $100 \%$ \\
\hline Andesita cuarz. & $\mathrm{o}$ & $0,00 \%$ & $\mathrm{o}$ & $0,00 \%$ & 2 & $100 \%$ & o & $0,00 \%$ & 0 & $0,00 \%$ & $\mathrm{o}$ & $0,00 \%$ & 2 & $100 \%$ \\
\hline Andesita silicif. & o & $0,00 \%$ & 4 & $9,76 \%$ & 35 & $85,37 \%$ & o & $0,00 \%$ & o & o,oo\% & 2 & $4,88 \%$ & 41 & $100 \%$ \\
\hline Basalto 1 & o & ०,००\% & 23 & $2,55 \%$ & 694 & $77,03 \%$ & 140 & $15,54 \%$ & 2 & $0,22 \%$ & 42 & $4,66 \%$ & 901 & $100 \%$ \\
\hline Basalto 2 & $\mathrm{o}$ & $0,00 \%$ & 13 & $17,57 \%$ & 58 & $78,38 \%$ & o & $0,00 \%$ & $\mathrm{o}$ & $0,00 \%$ & 3 & $4,05 \%$ & 74 & $100 \%$ \\
\hline Calcedonia & $\mathrm{o}$ & $0,00 \%$ & $\mathrm{o}$ & ०,००\% & 1 & $100 \%$ & $\mathrm{o}$ & $0,00 \%$ & o & $0,00 \%$ & $\mathrm{o}$ & $0,00 \%$ & 1 & $100 \%$ \\
\hline Cuarzo & 10 & $3,34 \%$ & 8 & $2,68 \%$ & 255 & $85,28 \%$ & 2 & $0,67 \%$ & 1 & $0,33 \%$ & 23 & $7,69 \%$ & 299 & $100 \%$ \\
\hline Metacuarcita & 3 & $8,57 \%$ & 3 & $8,57 \%$ & 23 & $65,71 \%$ & $\mathrm{o}$ & $0,00 \%$ & 1 & $2,86 \%$ & 5 & $14,29 \%$ & 35 & $100 \%$ \\
\hline M P no diferenciadas & o & $0,00 \%$ & 1 & $50,00 \%$ & & & $\mathrm{o}$ & $0,00 \%$ & o & $0,00 \%$ & 1 & $50,00 \%$ & 2 & $100 \%$ \\
\hline Obs. Ona & o & $0,00 \%$ & $\mathrm{o}$ & $0,00 \%$ & 17 & $89,47 \%$ & $\mathrm{o}$ & $0,00 \%$ & o & $0,00 \%$ & 2 & $10,53 \%$ & 19 & $100 \%$ \\
\hline Obs. Cueros de Purulla & $\mathrm{o}$ & ०,००\% & o & ०,००\% & 1 & $100 \%$ & $\mathrm{o}$ & $0,00 \%$ & o & ०,००\% & $\mathrm{o}$ & $0,00 \%$ & 1 & $100 \%$ \\
\hline Obs. Laguna Cavi & $\mathrm{o}$ & $0,00 \%$ & $\mathrm{o}$ & $0,00 \%$ & 3 & $100 \%$ & $\mathrm{o}$ & $0,00 \%$ & $\mathrm{o}$ & $0,00 \%$ & $\mathrm{o}$ & $0,00 \%$ & 3 & $100 \%$ \\
\hline Toba dacítica & $\mathrm{o}$ & $0,00 \%$ & $\mathrm{o}$ & o,o०\% & 1 & $100 \%$ & o & $0,00 \%$ & o & $0,00 \%$ & $\mathrm{o}$ & $0,00 \%$ & 1 & $100 \%$ \\
\hline Vulcanita VcF & $\mathrm{o}$ & $0,00 \%$ & 1 & $100 \%$ & & & $\mathrm{o}$ & $0,00 \%$ & o & $0,00 \%$ & o & $0,00 \%$ & 1 & $100 \%$ \\
\hline $\begin{array}{l}\text { Vulc. no } \\
\text { diferenciadas }\end{array}$ & $\mathrm{o}$ & $0,00 \%$ & 12 & $24,00 \%$ & 33 & $66,00 \%$ & $\mathrm{o}$ & $0,00 \%$ & o & $0,00 \%$ & 5 & $10,00 \%$ & 50 & $100 \%$ \\
\hline Vulcanita VcP & o & $0,00 \%$ & 3 & $13,64 \%$ & 19 & $86,36 \%$ & o & $0,00 \%$ & o & $0,00 \%$ & o & $0,00 \%$ & 22 & $100 \%$ \\
\hline Totales & 13 & $0,87 \%$ & 72 & $4,81 \%$ & 1.179 & $78,81 \%$ & 142 & $9,49 \%$ & 4 & $0,27 \%$ & 86 & $5,75 \%$ & 1.496 & $100 \%$ \\
\hline
\end{tabular}

Tabla 2. Frecuencias absolutas y porcentuales de las categorías de origen de las extracciones por materia prima (subgrupo productos bipolares enteros y fracturados + lascas enteras + lascas fracturadas con talón + lascas fracturadas sin talón, $n=1.496$ )

En cuanto a las variables dimensionales de los desechos, hay una predominancia marcada de los desechos de tamaño relativo pequeño $(61,30 \%, \mathrm{n}=369)$, seguida por los desechos muy pequeños $(20,43 \%, \mathrm{n}=123)$ y mediano-pequeños $(15,12 \%, \mathrm{n}=91)$ (Figura 2). Este es el caso en la mayoría de las materias primas. Luego hay proporciones menores (entre el $0,77 \%$ y el 10,81\%) de tamaño mediano-grande y grande en las rocas más frecuentes, es decir, basalto Bs1, cuarzo y basalto Bs2. Solo se registró un desecho de tamaño muy grande, correspondiente a la vulcanita no diferenciada.

Asimismo, en todas las materias primas predominan los desechos de espesor relativo muy delgado - menores a $5 \mathrm{~mm}-(79,57 \%, \mathrm{n}=479)$ y se observa un decrecimiento de las frecuencias a medida que los espesores se hacen mayores (delgado $17,11 \%, \mathrm{n}=103$ y grueso $3,32 \%, \mathrm{n}=20$ ) (Figura 2).

Con respecto a los módulos de longitud/anchura, si bien hay una preponderancia general de los desechos cortos (particularmente muy anchos y anchos), cuando se analizan estas frecuencias en relación con las materias primas se observan tres tendencias (Figura 3). En primer lugar, notablemente en los casos del cuarzo y la metacuarcita, y menos acentuadamente en el caso de la andesita silicificada, puede observarse una tendencia decreciente en cuanto a su representatividad numérica, a medida que los módulos se hacen más cortos y más anchos. La segunda tendencia es opuesta a la primera y se observa de forma exclusiva en el caso del basalto Bs1, el cual exhibe una representatividad cada vez mayor a medida que los módulos se acortan y ensanchan. En tercer lugar, el resto de las materias primas tienen una distribución más homogénea entre los módulos medianos y cortos. 


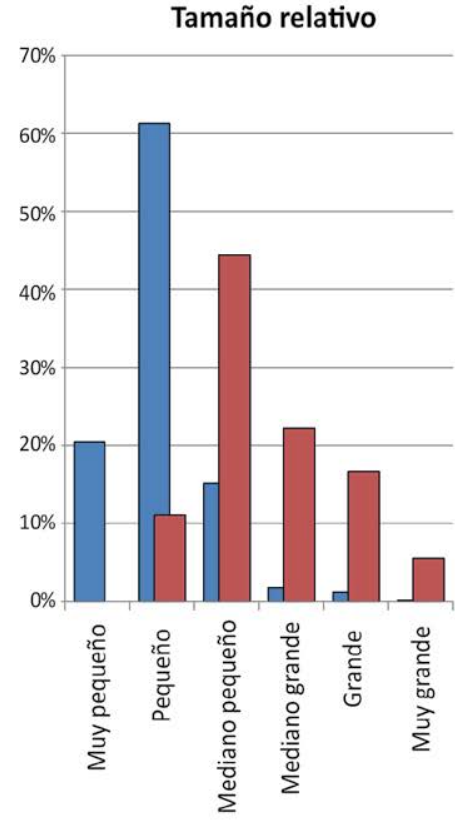

Desechos

Instrumentos
Módulo longitud/anchura

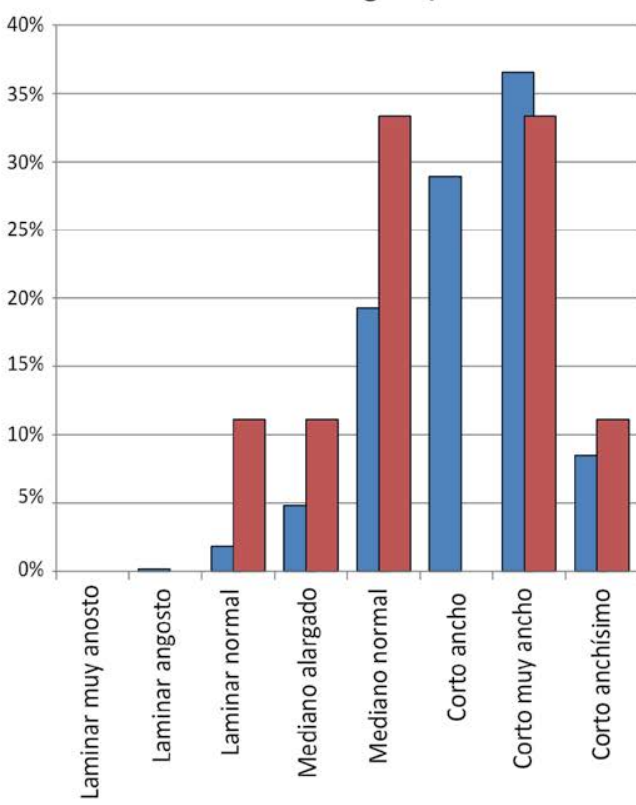

Desechos $\square$ Instrumentos
Espesor relativo

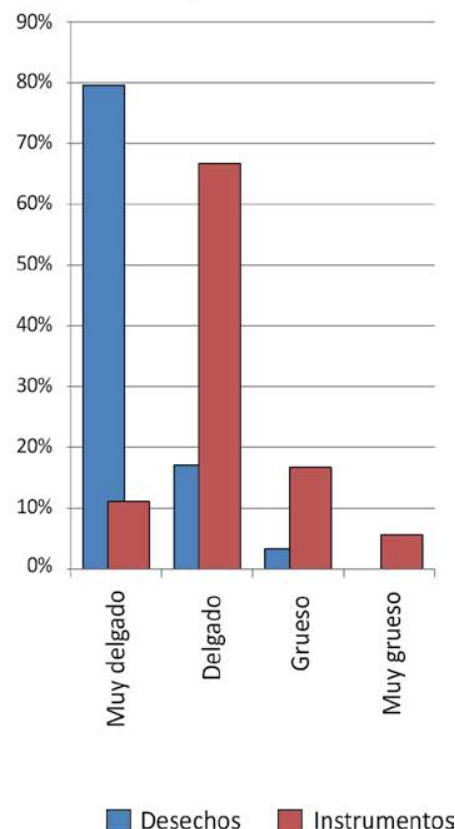

Figura 2. Comparación de las frecuencias porcentuales de las categorías de tamaño relativo, módulo de longitud/anchura y espesor relativo para las clases tipológicas 'desechos de talla' (subgrupo lascas enteras + productos bipolares enteros, $n=602$ ) versus 'instrumentos' (subgrupo enteros, $n=18$ ).

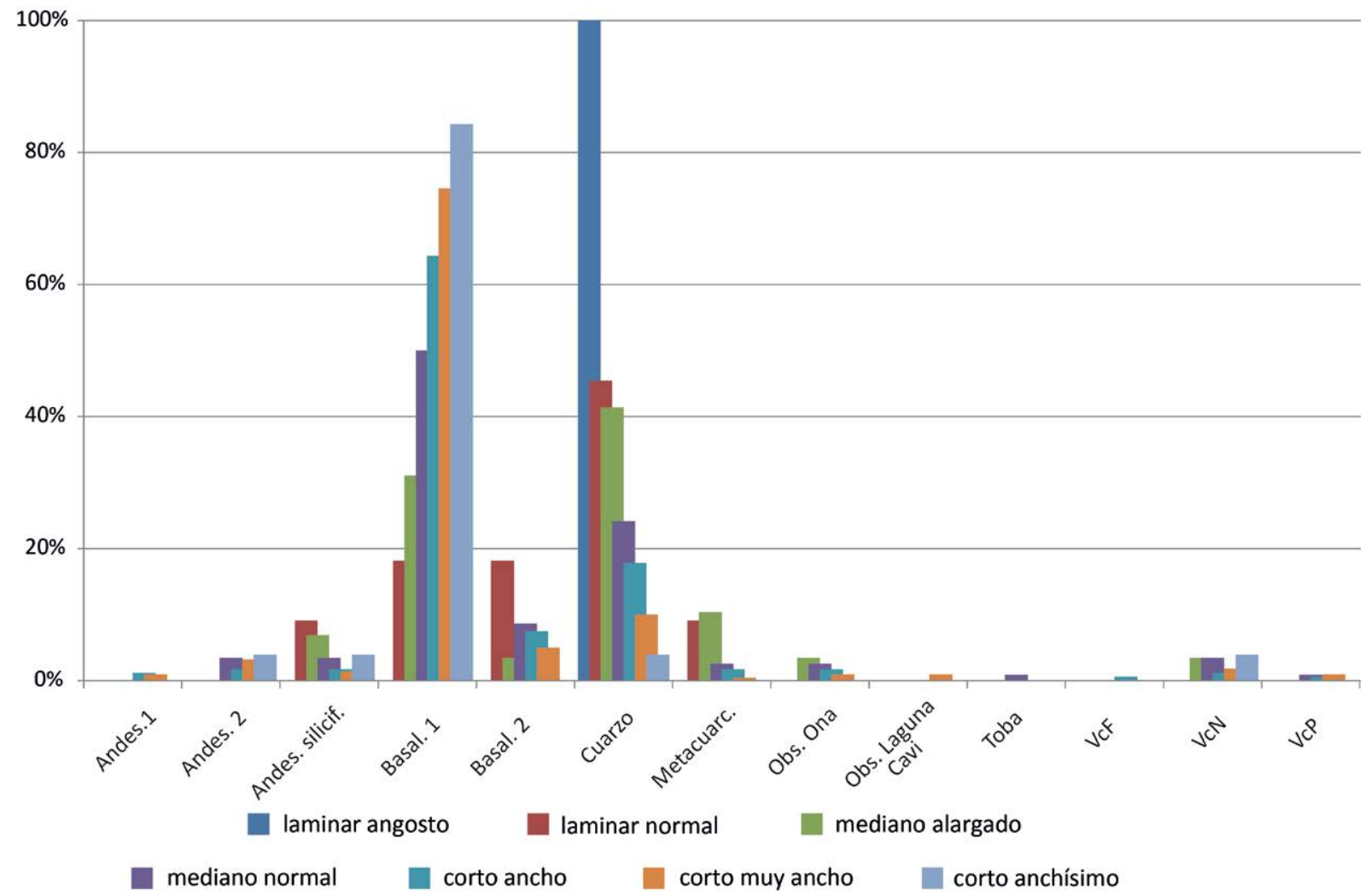

Figura 3. Frecuencias porcentuales de materia prima por categoría de módulo longitud/anchura para la clase 'desechos', subgrupo productos bipolares enteros + lascas enteras $(n=602)$. 
En cuanto al origen de las extracciones, predominan marcadamente las lascas internas en el conjunto (Tabla 2). Con una gran diferencia porcentual siguen las lascas de reactivación de filos, luego las lascas no diferenciadas y las lascas externas. Finalmente, se presentan valores muy escasos de productos bipolares y de lascas de reactivación de núcleo. Ahora bien, las lascas internas son predominantes en la mayoría de las materias primas y las externas se registran en casi todos los casos. En cambio, las lascas de reactivación de filos están presentes sólo en el basalto Bs1 $(15,54 \%)$ y el cuarzo $(0,67 \%)$. Por su parte, las lascas de reactivación de núcleos están presentes en el basalto Bs1, en el cuarzo y en la metacuarcita. Finalmente, los productos bipolares se registran exclusivamente en el cuarzo y la metacuarcita (Tabla 2).

La mayoría de los desechos $(72,09 \%, \mathrm{n}=434)$ no presentan restos de corteza en su cara dorsal, y el promedio de porcentaje de corteza para los desechos es bajo - del orden del 10\%-. Los productos bipolares, las lascas de reactivación de núcleos y las lascas no diferenciadas no presentan ningún espécimen con reserva de corteza (Andrefsky, 1998; Sullivan y Rozen, 1985). En cuanto a las lascas internas, más del $90 \%$ presenta porcentajes de corteza menores al 50\%. Un dato llamativo es que el $69,89 \%$ de las lascas de reactivación de filos presenta cierta proporción de corteza en su cara dorsal.

Finalmente, cabe mencionar que más de la mitad de los desechos de talla $(58,96 \%)$ presentan trabajos de regularización del frente de extracción.

\section{Núcleos}

En el conjunto analizado se registró un fragmento no diferenciado de núcleo, confeccionado sobre basalto Bs1. Su estado fragmentario limita las observaciones a realizar, especialmente en relación con sus valores para las variables dimensionales. No pudo diferenciarse la forma base que se utilizó, aunque se observa la ausencia total de corteza. La forma del núcleo es de tipo no diferenciada y la/s plataforma/s de percusión han sido eliminadas por la fractura.

\section{Instrumentos}

Esta clase incluyó artefactos formatizados ( $\mathrm{n}=65)$, artefactos no formatizados con filos, puntas y/o superficies con rastros complementarios $(\mathrm{n}=4)$ y litos no diferenciados modificados por uso $(n=3)$, lo cual totaliza 72 artefactos. El registro de cuatro instrumentos dobles y 13 compuestos arroja un total de 95 filos, puntas y/o superficies modificadas, entre los cuales se registran 15 grupos tipológicos (Tabla 3, Figura 4). En los artefactos compuestos no se han podido identificar elementos que permitan discriminar entre grupos tipológicos básicos y complementarios (sensu Aschero, 1975), por lo cual se consideraron todos los grupos tipológicos generales de manera equivalente.

Dado que la tasa de fragmentación de los instrumentos es alta (75\%), resulta lógico que el grupo más representado sea el de los fragmentos no diferenciados de artefactos formatizados $(26,32 \%, n=25)$. Luego, continúan las raederas $(14,74 \%, n=14) y$, con menores porcentajes, los filos y puntas naturales con rastros complementarios $(8,42 \%, \mathrm{n}=8)$, los artefactos de formatización sumaria $(8,42 \%, \mathrm{n}=8)$, las muescas $(6,32 \%, \mathrm{n}=6)$, los denticulados $(6,32 \%, \mathrm{n}=6)$, los artefactos burilantes $(5,26 \%, \mathrm{n}$ $=5)$, los artefactos mediano pequeños/muy pequeños con retoque en bisel oblicuo (R.B.O.) $(5,26 \%, \mathrm{n}=5)$, los litos no diferenciados modificados por uso $(5,26 \%, \mathrm{n}=5)$ y los perforadores $(4,21 \%, n=4)$. Finalmente, se registran escasos cuchillos $(n=2)$, 


\begin{tabular}{|c|c|c|c|c|c|}
\hline \multicolumn{3}{|l|}{ Grupo tipológico } & \multicolumn{3}{|l|}{ Subgrupo } \\
\hline & $\mathrm{n}$ & $\%$ & & $\mathrm{n}$ & $\%$ \\
\hline Raederas & 14 & $14,74 \%$ & $\begin{array}{l}\text { Filo frontal largo } \\
\text { Filos convergentes en ápice romo } \\
\text { Fragmento no diferenciado }\end{array}$ & $\begin{array}{l}6 \\
2 \\
6\end{array}$ & $\begin{array}{l}6,32 \% \\
2,11 \% \\
6,32 \%\end{array}$ \\
\hline R.B.O. & 5 & $5,26 \%$ & $\begin{array}{l}\text { Filo frontal } \\
\text { Filo lateral }\end{array}$ & $\begin{array}{l}3 \\
2\end{array}$ & $\begin{array}{l}3,16 \% \\
2,11 \%\end{array}$ \\
\hline Cuchillos & 2 & $2,11 \%$ & $\begin{array}{l}\text { Filo retocado lateral sin ápice activo } \\
\text { Filo natural con dorso formatizado }\end{array}$ & $\begin{array}{l}1 \\
1\end{array}$ & $\begin{array}{l}1,05 \% \\
1,05 \%\end{array}$ \\
\hline Cortantes o trinchetas & 2 & $2,11 \%$ & $\begin{array}{l}\text { Filo frontal retocado } \\
\text { Filo lateral retocado }\end{array}$ & $\begin{array}{l}1 \\
1\end{array}$ & $\begin{array}{l}1,05 \% \\
1,05 \%\end{array}$ \\
\hline Muescas & 6 & $6,32 \%$ & $\begin{array}{l}\text { Filo frontal } \\
\text { Fragmento no diferenciado }\end{array}$ & $\begin{array}{l}4 \\
2\end{array}$ & $\begin{array}{l}4,21 \% \\
2,11 \%\end{array}$ \\
\hline Denticulados & 6 & $6,32 \%$ & $\begin{array}{l}\text { Filo lateral largo } \\
\text { Fragmento no diferenciado }\end{array}$ & $\begin{array}{l}4 \\
2\end{array}$ & $\begin{array}{l}4,21 \% \\
2,11 \%\end{array}$ \\
\hline Artefactos burilantes & 5 & $5,26 \%$ & $\begin{array}{l}\text { Angular } \\
\text { Retoque alternante axial } \\
\text { Fragmento no diferenciado }\end{array}$ & $\begin{array}{l}3 \\
1 \\
1\end{array}$ & $\begin{array}{l}3,16 \% \\
1,05 \% \\
1,05 \%\end{array}$ \\
\hline Perforadores & 4 & $4,21 \%$ & $\begin{array}{l}\text { Triédrica asimétrica s/base formatizada } \\
\text { Triédrica asimétrica s/base no formatizada }\end{array}$ & $\begin{array}{l}1 \\
3\end{array}$ & $\begin{array}{l}1,05 \% \\
3,16 \%\end{array}$ \\
\hline Puntas de proyectil & 1 & $1,05 \%$ & Fragmento de limbo & 1 & $1,05 \%$ \\
\hline F.N.C.R. & 7 & $7,37 \%$ & $\begin{array}{l}\text { Frontal } \\
\text { Lateral }\end{array}$ & $\begin{array}{l}4 \\
3\end{array}$ & $\begin{array}{l}4,21 \% \\
3,16 \% \\
\end{array}$ \\
\hline P.N.C.R. & 1 & $1,05 \%$ & Axial & 1 & $1,05 \%$ \\
\hline Artefacto Formatización Sumaria & 8 & $8,42 \%$ & $\begin{array}{l}\text { Con retoque/microrretoque sumario } \\
\text { Fragmento no diferenciado }\end{array}$ & $\begin{array}{l}7 \\
1\end{array}$ & $\begin{array}{l}7,37 \% \\
1,05 \%\end{array}$ \\
\hline Fragmento no diferenciado de artefacto & 25 & $26,32 \%$ & $\begin{array}{l}\text { Fragmento de filo } \\
\text { Fragmento de artefacto }\end{array}$ & $\begin{array}{c}18 \\
7\end{array}$ & $\begin{array}{l}18,95 \% \\
7,37 \%\end{array}$ \\
\hline Semimuescas & 2 & $2,11 \%$ & $\begin{array}{l}\text { Filo lateral } \\
\text { Fragmento no diferenciado }\end{array}$ & $\begin{array}{l}1 \\
1\end{array}$ & $\begin{array}{l}1,05 \% \\
1,05 \%\end{array}$ \\
\hline Filo bifacial de arista sinuosa & 2 & $2,11 \%$ & Filo frontal & 2 & $2,11 \%$ \\
\hline $\begin{array}{l}\text { Litos no diferenciados } \\
\text { modificados por uso }\end{array}$ & 5 & $5,26 \%$ & $\begin{array}{l}\text { Frontal } \\
\text { Fragmento no diferenciado }\end{array}$ & $\begin{array}{l}4 \\
1\end{array}$ & $\begin{array}{l}4,21 \% \\
1,05 \%\end{array}$ \\
\hline Total & 95 & $100 \%$ & & 95 & $100 \%$ \\
\hline
\end{tabular}

Tabla 3. Frecuencias absolutas y porcentuales de los grupos y subgrupos tipológicos presentes en el conjunto artefactual analizado $(n=95$ filos, puntas o superficies activas). Referencias: R.B.O.: artefactos mediano-pequeños/muy pequeños con retoque en bisel oblicuo; F.N.C.R.: filo natural con rastros complementarios; P.N.C.R.: punta natural con rastros complementarios.

3. Para la descripción de las semimuescas, consultar Sentinelli (2012). cortantes $(n=2)$, semimuescas ${ }^{3}(n=2)$, filos bifaciales de arista sinuosa $(n=2)$ y un fragmento de limbo de punta de proyectil (Tabla 3 ).

Entre los instrumentos se registró un menor rango de materias primas que entre los desechos, sin embargo, las rocas metamórficas foliadas - ausentes entre los desechos de talla - se encuentran representadas entre los instrumentos con la tercera frecuencia porcentual $(8,33 \%, \mathrm{n}=6)$. Al igual que con los desechos, entre los instrumentos también predominan marcadamente las materias primas locales, las de disponibilidad mediata son predominantes frente a las inmediatas y dentro de las rocas mediatas son preponderantes aquellas de disponibilidad lejana. La proporción de las materias primas 


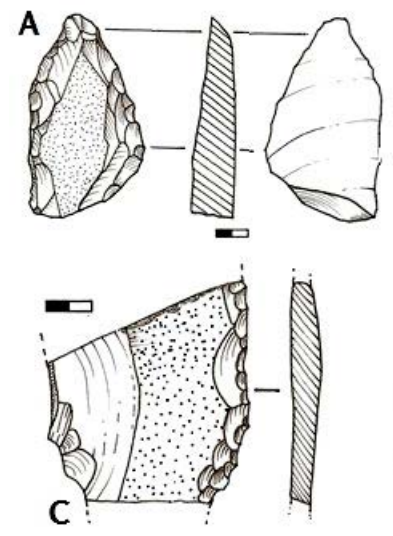

B
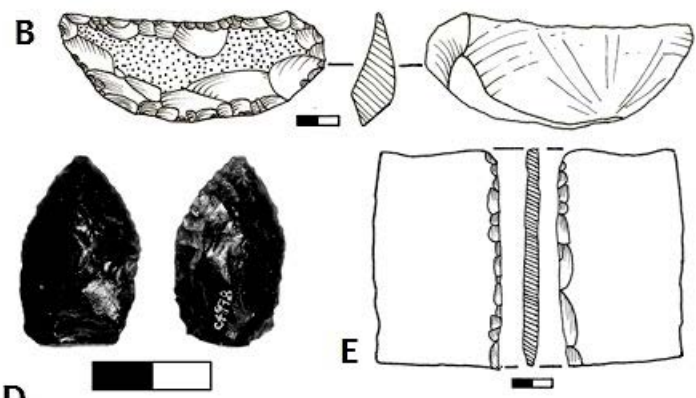

-
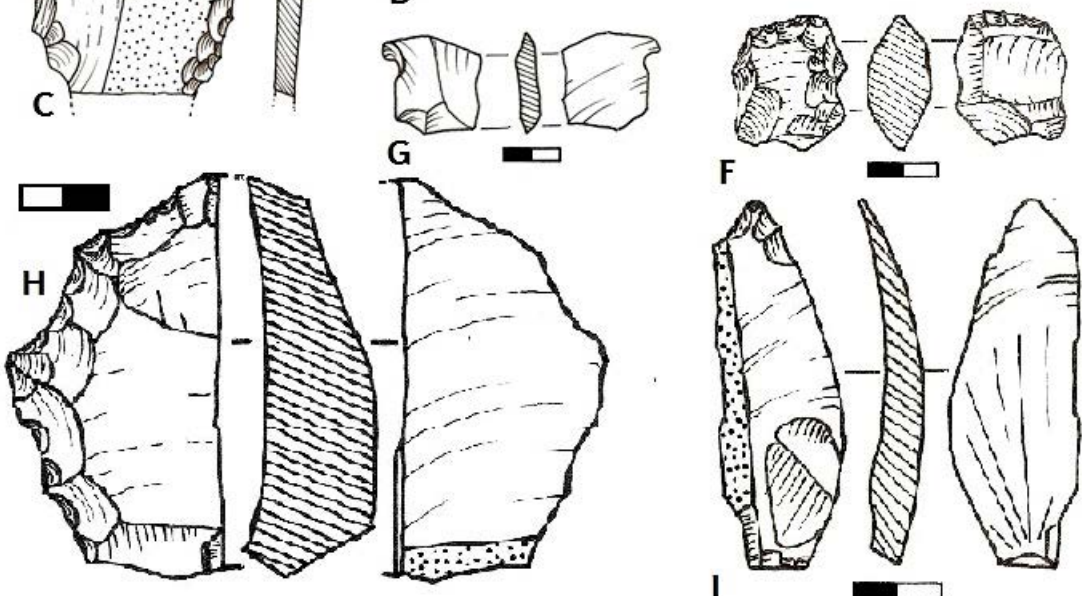

$\mathbf{F}$
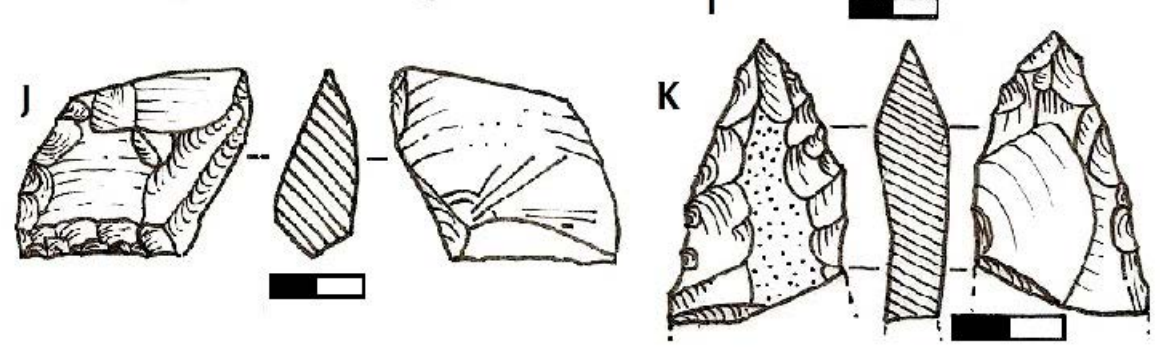

Figura 4. Grupos tipológicos formatizados por talla. $A, B$ y $C$ ) raederas ( $A$ : filos convergentes en ápice romo, $B$ : filo frontal largo - sobre lasca de reactivación-, C: fragmento de raedera); $D$ y $E$ ) cuchillos. ( $D$ : filo lateral con ápice activo - sobre punta de proyectil retomada-, E: filo lateral, sin ápice activo - sobre roca metamórfica foliada -); F) artefacto cortante de filo frontal retocado; G). muesca retocada lateral; $H$ ) artefacto denticulado, filo lateral largo; I) perforador de punta triédrica, sección asimétrica; J) artefacto mediano pequeño/muy pequeño R.B.O. de filo lateral; K) fragmento de limbo de punta de proyectil.

no locales entre los instrumentos es casi el triple de la que presentan los desechos (Tabla 1). Esto puede estar indicando que estas rocas eran escasamente talladas dentro de la estructura, es decir, que ingresaban a ésta en la forma de instrumentos terminados o en avanzado estado de formatización, requiriendo un mínimo trabajo de formatización y/o mantenimiento.

En cuanto a la distribución de los grupos tipológicos entre las diferentes materias primas, es marcada la ubicuidad y predominancia del basalto Bs1 en la mayoría de los grupos y su representación exclusiva en las raederas, filos bifaciales de arista sinuosa y punta de proyectil. Por su parte, el cuarzo está representado en ocho grupos tipológicos, aunque no predomina en ninguno de ellos. Las distintas variedades de obsidianas aparecen entre los artefactos mediano-pequeños/muy pequeños R.B.O., los cortantes, los cuchillos y los fragmentos no diferenciados de artefactos formatizados. Otras materias primas restringidas a algunos grupos son la andesita An1 (semimuescas y filos/puntas naturales con rastros complementarios), la toba dacítica (denticulados) y 
la metacuarcita (artefactos de formatización sumaria). Las rocas metamórficas foliadas fueron usadas mayoritariamente como soporte para artefactos con filos naturales con rastros complementarios y litos no diferenciados modificados por uso (a excepción de un cuchillo de filo retocado) (Figura 5).

En cuanto a las variables dimensionales, los tamaños relativos de los instrumentos presentan un desfasaje con respecto a los tamaños de los desechos, los cuales son en su gran mayoría, demasiado pequeños para haber podido constituir potenciales formas base de los instrumentos del conjunto analizado (Figura 2). Asimismo, la mayoría de los instrumentos tienen un espesor relativo mayor que el de los desechos de talla (Figura 2). En cuanto a los módulos de longitud/anchura, también se observa una discrepancia en la comparación entre los instrumentos y los desechos (Figura 2), con la excepción de la categoría "corto muy ancho", de importante frecuencia en ambas clases tipológicas.

Los instrumentos fueron confeccionados en su mayoría sobre lascas de diferentes tipos $(88,89 \%, \mathrm{n}=64) \mathrm{y}$, en menor medida, sobre lajas y guijarros $(6,95 \%, \mathrm{n}=5)$, sobre un nódulo, sobre una forma base no diferenciada y sobre un artefacto formatizado que fue retomado. Los tipos de lascas utilizadas comprenden mayoritariamente lascas indiferenciadas $(61,11 \%, \mathrm{n}=45)$, angulares $(16,67 \%, \mathrm{n}=12)$, primarias $(6,94 \%, \mathrm{n}=4)$, de reactivación directa $(2,78 \%, \mathrm{n}=2)$ y de dorso natural $(1,39 \%, \mathrm{n}=1)$. La significativa representación de las lascas no diferenciadas puede relacionarse con el alto grado de fracturación de los instrumentos, que impide la identificación de los tipos de lasca utilizados como formas base. Las lascas primarias, de dorso natural y de reactivación directa sólo se aprovecharon como formas base en el caso del basalto Bs1, que es la materia prima que presenta la mayor variedad de formas base.

Solamente en las rocas metamórficas foliadas y la obsidiana de Laguna Cavi se verifica el aprovechamiento de formas base diferentes a las lascas. En la obsidiana se ha registrado la utilización de un artefacto formatizado retomado (una punta de proyectil) para confeccionar un cuchillo de filo retocado. En las rocas metamórficas foliadas se observa la utilización de lajas no rodadas, guijarros y nódulos tabulares como formas base. Esta situación seguramente está determinada por las características de clivaje y fractura que presenta naturalmente esta materia prima debido a su textura esquistosa, situación que puede relacionarse también con la utilización mayoritaria de estas rocas como soportes de artefactos no formatizados por lascados, como los filos naturales con rastros complementarios y los litos no diferenciados modificados por uso (Figura 5).

\section{$\underline{\text { Situación de los lascados, serie técnica y clase técnica }}$}

Estas variables se relacionan con la confección de filos por lascado, por eso la variable 'serie técnica' no ha sido aplicada a los litos no diferenciados modificados por uso, la variable 'situación de los lascados' no se aplicó a los litos no diferenciados modificados por uso ni a los filos/puntas naturales con rastros complementarios, y la variable 'clase técnica' (Aschero y Hocsman, 2004; Hocsman y Escola, 2006-07) no fue aplicada a los artefactos que presentan sólo filos o puntas naturales con rastros complementarios ni a los litos no diferenciados modificados por uso.

Acerca de la situación de los lascados (Tabla 4), la mayoría de los filos han sido confeccionados por el lascado de una de sus caras, es decir, que son mayoritariamente filos unifaciales, tanto directos como inversos, aunque también se registraron filos bifaciales, alternantes y alternos.

La variable serie técnica informa sobre tres características relacionadas con la forma de confección de los filos o puntas obtenidas por lascado: la anchura de los lascados sobre 


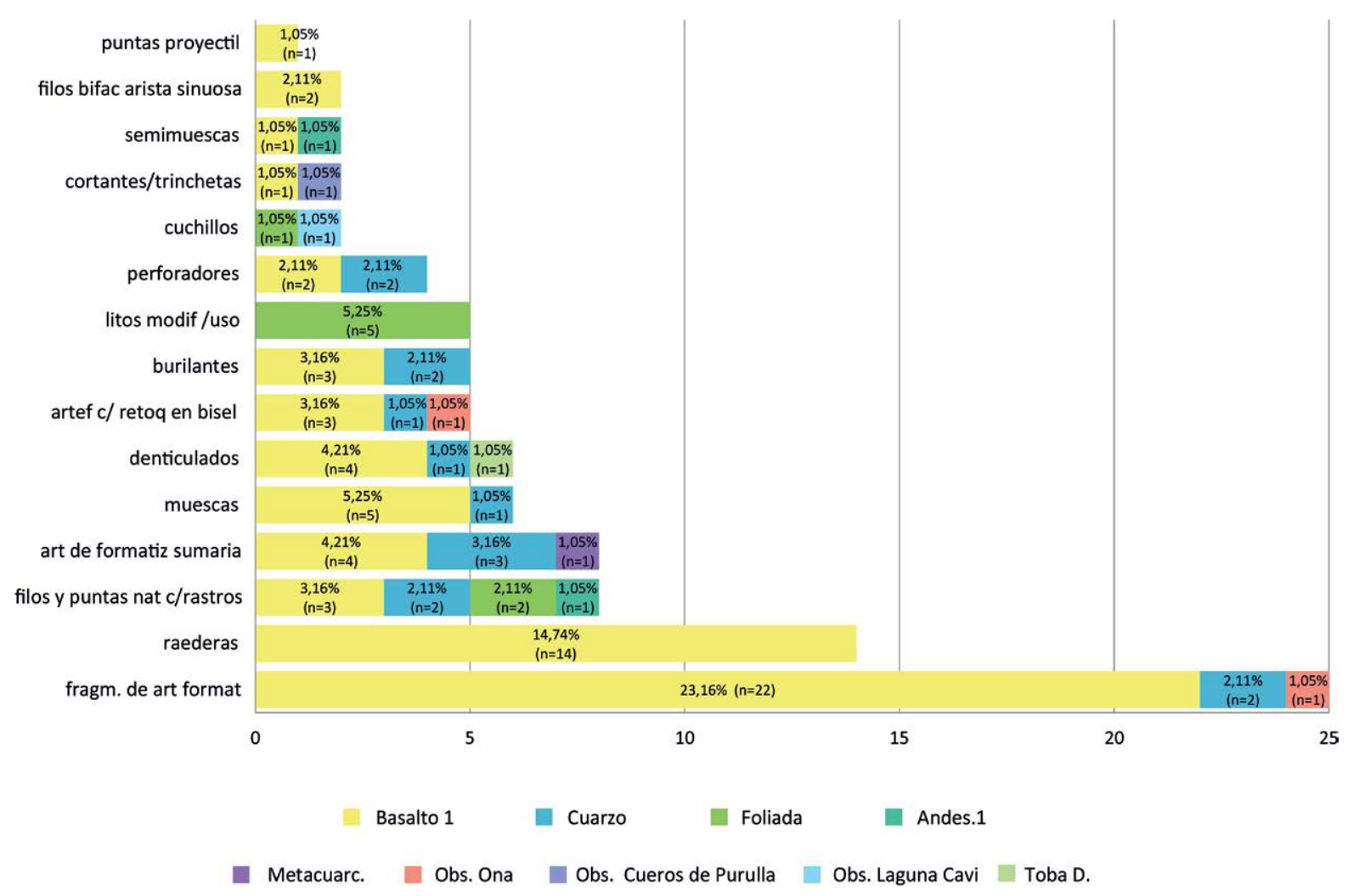

Figura 5. Frecuencias absolutas de las diferentes categorías de grupo tipológico por categoría de materia prima para el conjunto de los grupos tipológicos $(n=95)$.

el borde, la extensión de los lascados sobre las caras del instrumento y la presencia o ausencia de técnica bipolar en la confección. En el conjunto estudiado se pueden realizar dos observaciones importantes: en primer lugar, la ausencia de filos confeccionados mediante la técnica bipolar - a pesar de la presencia de productos bipolares entre los desechos- $y$, en segundo lugar, la presencia de series técnicas compuestas, es decir, de filos confeccionados mediante el empleo de más de una técnica de formatización. De hecho, la serie técnica compuesta por la utilización de retalla marginal y retoque marginal comprende el 46,67\% $(n=42)$ de los filos confeccionados por lascado, seguida por la utilización exclusiva de retoque marginal $(35,56 \%, \mathrm{n}=32)$. El 87,78\% $(\mathrm{n}=79)$ de los filos analizados ha sido manufacturado a través de retoque y dentro de ese grupo en casi la mitad de los casos el retoque ha sido precedido por retalla $(48,89 \%, \mathrm{n}=44)$ y en algunos pocos casos por lascado simple $(2,22 \%, \mathrm{n}=2)$. La formatización por retalla se encuentra en la mitad de los filos analizados $(n=45)$ aunque sólo se halla como técnica exclusiva de formatización en un caso. El microretoque tiene una ínfima presencia en el conjunto (un solo caso). El lascado simple se registra en un caso como serie técnica exclusiva y en dos casos precediendo el retoque marginal. Por su parte, ocho instrumentos presentan sólo un trabajo de talla de extracción sin formatización posterior (filos y puntas naturales).

En cuanto a la extensión de los lascados sobre las caras, en la mayoría de los casos es de carácter marginal $(87,78 \%, \mathrm{n}=79)$. Sólo en el caso de una raedera y un fragmento no diferenciado de filo formatizado se registra una cobertura parcialmente extendida de las caras y el trabajo extendido sólo se registró en el cuchillo confeccionado sobre la punta de proyectil de obsidiana.

Finalmente, en el conjunto instrumental analizado, la clase técnica marcadamente predominante es el trabajo no invasivo unifacial $(83,08 \%, \mathrm{n}=54)$ y se registran escasos 


\begin{tabular}{|c|c|c|c|c|c|c|}
\hline \multirow[b]{2}{*}{ Grupos tipológicos } & \multicolumn{6}{|c|}{ Situación de los lascados } \\
\hline & $\begin{array}{l}\text { Unifacial } \\
\text { Directo }\end{array}$ & $\begin{array}{l}\text { Unifacial } \\
\text { Inverso }\end{array}$ & Bifacial & Alterno & Alternante & Totales \\
\hline Raederas & $\begin{array}{c}13 \\
92,86 \%\end{array}$ & $\begin{array}{c}0 \\
0,00 \%\end{array}$ & $\begin{array}{c}1 \\
7,14 \%\end{array}$ & $\begin{array}{c}0 \\
0,00 \%\end{array}$ & $\begin{array}{c}0 \\
0,00 \%\end{array}$ & $\begin{array}{c}14 \\
14,74 \%\end{array}$ \\
\hline R.B.O. & $\begin{array}{c}4 \\
80,00 \%\end{array}$ & $\begin{array}{c}1 \\
20,00 \%\end{array}$ & $\begin{array}{c}0 \\
0,00 \%\end{array}$ & $\begin{array}{c}0 \\
0,00 \%\end{array}$ & $\begin{array}{c}0 \\
0,00 \%\end{array}$ & $\begin{array}{c}5 \\
5,25 \%\end{array}$ \\
\hline Cuchillos & $\begin{array}{c}0 \\
0,00 \%\end{array}$ & $\begin{array}{c}0 \\
0,00 \%\end{array}$ & $\begin{array}{c}2 \\
100,00 \%\end{array}$ & $\begin{array}{c}0 \\
0,00 \%\end{array}$ & $\begin{array}{c}0 \\
0,00 \%\end{array}$ & $\begin{array}{c}2 \\
2,11 \%\end{array}$ \\
\hline Cortantes o trinchetas & $\begin{array}{c}0 \\
0,00 \%\end{array}$ & $\begin{array}{c}1 \\
50,00 \%\end{array}$ & $\begin{array}{c}1 \\
50,00 \%\end{array}$ & $\begin{array}{c}0 \\
0,00 \%\end{array}$ & $\begin{array}{c}0 \\
0,00 \%\end{array}$ & $\begin{array}{c}2 \\
2,11 \%\end{array}$ \\
\hline Muescas & $\begin{array}{c}4 \\
66,67 \%\end{array}$ & $\begin{array}{c}2 \\
33,33 \%\end{array}$ & $\begin{array}{c}0 \\
0,00 \%\end{array}$ & $\begin{array}{c}0 \\
0,00 \%\end{array}$ & $\begin{array}{c}0 \\
0,00 \%\end{array}$ & $\begin{array}{c}6 \\
6,30 \%\end{array}$ \\
\hline Denticulados & $\begin{array}{c}1 \\
20,00 \% \\
\end{array}$ & $\begin{array}{c}2 \\
40,00 \% \\
\end{array}$ & $\begin{array}{c}0 \\
0,00 \% \\
\end{array}$ & $\begin{array}{c}1 \\
20,00 \% \\
\end{array}$ & $\begin{array}{c}1 \\
20,00 \% \\
\end{array}$ & $\begin{array}{c}5 \\
5,25 \% \\
\end{array}$ \\
\hline Artefactos burilantes & $\begin{array}{c}0 \\
0,00 \%\end{array}$ & $\begin{array}{c}4 \\
80,00 \%\end{array}$ & $\begin{array}{c}0 \\
0,00 \%\end{array}$ & $\begin{array}{c}0 \\
0,00 \%\end{array}$ & $\begin{array}{c}1 \\
20,00 \%\end{array}$ & $\begin{array}{c}5 \\
5,25 \%\end{array}$ \\
\hline Perforadores & $\begin{array}{c}4 \\
100 \%\end{array}$ & $\begin{array}{c}0 \\
0,00 \%\end{array}$ & $\begin{array}{c}0 \\
0,00 \%\end{array}$ & $\begin{array}{c}0 \\
0,00 \%\end{array}$ & $\begin{array}{c}0 \\
0,00 \%\end{array}$ & $\begin{array}{c}4 \\
4,21 \%\end{array}$ \\
\hline Puntas de proyectil & $\begin{array}{c}0 \\
0,00 \%\end{array}$ & $\begin{array}{c}0 \\
0,00 \%\end{array}$ & $\begin{array}{c}1 \\
100 \%\end{array}$ & $\begin{array}{c}0 \\
0,00 \%\end{array}$ & $\begin{array}{c}0 \\
0,00 \%\end{array}$ & $\begin{array}{c}1 \\
1,05 \%\end{array}$ \\
\hline $\begin{array}{l}\text { Artefactos de } \\
\text { formatización sumaria }\end{array}$ & $\begin{array}{c}7 \\
87,50 \% \\
\end{array}$ & $\begin{array}{c}1 \\
12,50 \% \\
\end{array}$ & $\begin{array}{c}0 \\
0,00 \%\end{array}$ & $\begin{array}{c}0 \\
0,00 \% \\
\end{array}$ & $\begin{array}{c}0 \\
0,00 \% \\
\end{array}$ & $\begin{array}{c}8 \\
8,42 \% \\
\end{array}$ \\
\hline $\begin{array}{l}\text { Fragm. de artefactos } \\
\text { formatizados }\end{array}$ & $\begin{array}{c}21 \\
84,00 \%\end{array}$ & $\begin{array}{c}2 \\
8,00 \%\end{array}$ & $\begin{array}{c}1 \\
4,00 \%\end{array}$ & $\begin{array}{c}0 \\
0,00 \%\end{array}$ & $\begin{array}{c}1 \\
4,00 \%\end{array}$ & $\begin{array}{c}25 \\
26,32 \%\end{array}$ \\
\hline Semimuescas & $\begin{array}{c}1 \\
50,00 \%\end{array}$ & $\begin{array}{c}1 \\
50,00 \%\end{array}$ & $\begin{array}{c}0 \\
0,00 \% \\
\end{array}$ & $\begin{array}{c}0 \\
0,00 \% \\
\end{array}$ & $\begin{array}{c}0 \\
0,00 \% \\
\end{array}$ & $\begin{array}{c}2 \\
2,11 \% \\
\end{array}$ \\
\hline $\begin{array}{l}\text { Filos bifaciales de } \\
\text { arista sinuosa }\end{array}$ & $\begin{array}{c}0 \\
0,00 \%\end{array}$ & $\begin{array}{c}0 \\
0,00 \% \\
\end{array}$ & $\begin{array}{c}2 \\
100 \%\end{array}$ & $\begin{array}{c}0 \\
0,00 \% \\
\end{array}$ & $\begin{array}{c}0 \\
0,00 \% \\
\end{array}$ & $\begin{array}{c}2 \\
2,11 \%\end{array}$ \\
\hline Totales & $\begin{array}{c}55 \\
67,90 \%\end{array}$ & $\begin{array}{c}14 \\
17,28 \%\end{array}$ & $\begin{array}{c}8 \\
9,88 \%\end{array}$ & $\begin{array}{c}1 \\
1,23 \%\end{array}$ & $\begin{array}{c}3 \\
3,70 \%\end{array}$ & $\begin{array}{c}81 \\
100 \%\end{array}$ \\
\hline
\end{tabular}

Tabla 4. Frecuencias absolutas y porcentuales para la variable situación de los lascados por grupo tipológico para el conjunto de filos manufacturados por lascados $(n=81$, no incluye litos no diferenciados modificados por uso ni filos/puntas naturales con rastros complementarios).

instrumentos confeccionados por trabajo no invasivo bifacial $(7,69 \%, \mathrm{n}=5)$, trabajo no invasivo alternante $(4,62 \%, \mathrm{n}=3)$, reducción bifacial $(3,08 \%, \mathrm{n}=2)$ y trabajo no invasivo alterno $(1,54 \%, \mathrm{n}=1)$.

\section{Resultados: instancias de las prácticas}

Por los datos recabados podemos relacionar los artefactos líticos con tres aspectos fundamentales de la vida material y social de los pobladores de Cardonal: a) la obtención de materias primas, b) la producción y mantenimiento de instrumentos de piedra tallada y c) su utilización en diferentes actividades. La separación en estas instancias se efectúa sólo a fines de organizar la discusión, ya que, en la vida cotidiana todas ellas se entrelazaron mutuamente compartiendo no sólo los materiales líticos sino también otras materias, personas, actividades, tiempos, necesidades, percepciones y relaciones sociales, en el marco de la reproducción material y social de los habitantes de Cardonal. 


\section{Dónde y cómo procurarse las piedras}

La variabilidad de potenciales disponibilidades de las rocas utilizadas permite inferir para cada caso las posibles prácticas de aprovisionamiento empleadas por los residentes de la vivienda. En el caso del cuarzo, esta constituye la única roca documentada como disponible de manera inmediata desde esta aldea. Obviamente, involucraba un aprovisionamiento de tipo directo (Meltzer, 1989), ya que constituía un recurso fácilmente accesible en todo momento para los residentes de la casa. A pesar de tratarse de un material de mala calidad para la talla, el cuarzo fue, por su cantidad, la segunda materia prima lítica más utilizada, lo que lleva a indagar sobre los factores de esta elección. En primer lugar, su abundancia e inmediatez podría brindar la posibilidad de un aprovechamiento no económico de esta materia prima. En segundo lugar, su alta dureza confiere a los filos una larga durabilidad, lo cual podría haberse aprovechado para la confección de variados grupos tipológicos.

Acerca de la primera alternativa, los datos recabados no evidencian actividades de producción tendientes a maximizar el aprovechamiento del cuarzo. Por el contrario, en esta materia prima se ha registrado una gran cantidad de desechos que han sido descartados aun pudiendo haber sido utilizados como formas base, una escasa inversión de trabajo en los artefactos formatizados, muy baja presencia de lascas de reactivación y la ausencia absoluta de instrumentos reactivados. Una excepción podría estar dada por la presencia de productos bipolares en cuarzo, ya que algunos autores han propuesto que esta técnica de talla maximiza el aprovechamiento de recursos líticos (Andrefsky, 1998; Civalero, 2006; Flegenheimer, Bayón y González de Bonaveri, 1995). Sin embargo, claramente el conjunto no da indicios de que su uso responda a esa necesidad. En este caso, la aplicación de talla bipolar constituiría una forma de producir lascas con biseles agudos sobre una materia prima en la que, por sus propiedades físicas, eso no se logra fácilmente mediante la talla directa (Baqueiro Vidal, 2006; Fábregas Valcarce y Rodríguez Rellán, 2008; Moreno y Sentinelli, 2014). En cuanto a la segunda alternativa, esto es, la selección del cuarzo para la confección de filos particulares que saquen partido de su dureza, esta roca fue usada como soporte para una significativa variedad de grupos tipológicos, sin predominar en ninguno de ellos, por lo que no puede establecerse ninguna tendencia en relación con la característica de durabilidad de los filos de cuarzo.

Por otra parte, el aprovisionamiento de las rocas locales mediatas pudo haber sido resuelto por los habitantes de la casa en forma conjunta con ciertas prácticas relacionadas con la subsistencia, en especial con la caza y el pastoreo, las cuales habrían aportado de manera significativa a la dieta de los pobladores (Izeta, 2007). Dichas actividades implican una dinámica de movilidad amplia a través de diferentes áreas del territorio local, estructurada en relación con la etología de las presas. Así, los habitantes de Cardonal pudieron aprovisionarse de las rocas localizadas en un radio de $25 \mathrm{~km}$ de manera directa, dentro de una estrategia de aprovisionamiento de tipo embedded, en el sentido que le dio Binford (1979) a ese término y aplicó Escola (2000) en el estudio de la producción lítica de sociedades agropastoriles puneñas.

Entre las rocas locales mediatas, ciertas diferencias cuantitativas entre cercanas y lejanas pueden relacionarse con distintos modos de aprovisionamiento. Las rocas disponibles dentro de un radio de $10 \mathrm{~km}$ son, en promedio, materias primas de buena calidad. Sin embargo, sus escasas frecuencias en el conjunto y la ausencia de varias de ellas entre los instrumentos sugieren que eran utilizadas de forma ocasional, complementaria a las rocas predominantes y restringidas a unos pocos instrumentos. A juzgar por las frecuencias de desechos de talla y sus variables dimensionales, dichos instrumentos habrían sido producidos y/o mantenidos en la cocina pero luego utilizados fuera de ella. Estas rocas posiblemente fueran obtenidas dentro de la misma estrategia embedded ya mencionada. 
Ahora bien, las rocas mediatas lejanas comprenden más del $80 \%$ de los artefactos hechos con materias primas locales, porcentaje que está sostenido por la frecuencia del basalto Bs1 en todas las clases tipológicas. Además, es interesante remarcar que esta roca presenta los mayores rangos de variabilidad en los atributos analizados, lo cual la involucra en un espectro más amplio de prácticas de producción lítica que los demás tipos de rocas. Esto permite pensar en que existió una valoración particular de esta materia prima de buena calidad. En ese marco, consideramos que el aprovisionamiento de esta materia prima se habría sostenido o bien mediante un acceso directo a las fuentes organizado separadamente a la obtención de las demás rocas locales implicando partidas dirigidas especialmente a su obtención, o bien mediante algún mecanismo diferencial de transporte de esta roca. Cualquiera haya sido la situación, el aprovisionamiento diferencial de esta roca se evidencia en la posibilidad de los talladores de contar con el basalto Bs1 en formas y tamaños que permitieran, por un lado, algunas actividades de reducción primaria en el sitio (a juzgar por el hecho de que el único núcleo de la E1 es de esta materia prima), la confección de instrumentos con requerimientos particulares (las raederas de módulo grandísimo) y, al mismo tiempo, amplia flexibilidad para producir una variedad de grupos tipológicos e instrumentos de distintos tamaños.

Retomando la definición de prácticas tecnológicas planteada en la introducción de este trabajo como formas de actuar institucionalizadas para lograr múltiples fines, se buscó enfocar el aporte de la tecnología lítica a las estrategias de reproducción social: aquellas que el grupo pone en funcionamiento para transmitir a la siguiente generación todo lo que considera importante. En este sentido, sostenemos que las prácticas implicadas en el aprovisionamiento de rocas sustentan la reproducción material y social de la producción lítica, al transformar una característica de la naturaleza (afloramientos de rocas) en una característica del paisaje apropiado (fuentes de materias primas). Las elecciones de los talladores en relación con la obtención de materias primas debieron involucrar no sólo consideraciones acerca de las distancias a las distintas fuentes sino además otras valoraciones y percepciones culturales: apreciaciones acerca de las rocas y de las fuentes (mejor o menor calidad para la talla, cantidad y forma en que se presenta la roca - grandes bloques, pequeños nódulos, etc.-, cualidades estéticas -colores, brillos, opacidad/transparencia-); posibilidades de aprovisionamiento en relación con la organización de las prácticas de subsistencia; requerimientos de la producción lítica (instrumentos a confeccionar, exigencias de uso) y de la producción de otras tecnofacturas y tareas cotidianas (construcción y mantenimiento de las casas, los corrales, etc.), entre otros aspectos.

Estas valoraciones - sobre las cuales, por ahora, sólo nos permitimos hipotetizarpodrían haber determinado en gran medida que el basalto Bs1 haya sido el tipo de roca más utilizada por los talladores de Cardonal a pesar de su disponibilidad mediata lejana y la existencia de una buena provisión cercana de otras materias primas locales. Sin duda, estas valoraciones y percepciones fueron una parte importante de aquello que la sociedad de Cardonal buscaba transmitir a las siguientes generaciones. En este sentido, el aprovisionamiento directo de material lítico pudo haber sido una situación privilegiada para la trasmisión, entre talladores experimentados y aprendices, de algunos aspectos del habitus tecnológico asociados al aprovisionamiento de materias primas para la producción lítica, es decir, como estrategias para la reproducción social y material del grupo (Sentinelli, 2016).

En cuanto a las materias primas no locales, las obsidianas, teniendo en cuenta las distancias de las fuentes, su baja representación en el conjunto analizado de la cocina (y en el resto de la casa, de acuerdo a Cattáneo y Oliva, 2008 y Videla, 2011) y la virtual ausencia de corteza y de lascas externas de estas rocas, se considera probable que el acceso a ellas haya sido de tipo indirecto, por medio de su circulación e intercambio 
dentro de varias redes y esferas de interacción, que involucraban una gran variedad de objetos materiales y simbólicos (Lazzari et al., 2009; Scattolin et al., 2009a, 2009b).

En este contexto doméstico, las dimensiones y características de los instrumentos de obsidiana sumadas a la escasez de desechos de talla, sus tamaños, la ausencia de lascas externas y la alta proporción de regularización del frente de extracción, permiten plantear que su obtención ocurría en la forma de artefactos formatizados o lascas preparadas y seleccionadas para su formatización. Además, se registran algunos indicios de una valoración económica de las obsidianas, ya que se observan prácticas de producción tendientes a explotar al máximo esta materia prima no local de muy buena calidad, como es el reciclaje de instrumentos fracturados o agotados.

\section{La producción y mantenimiento de artefactos líticos}

A juzgar por la cantidad de desechos de talla recuperados, las prácticas de manufactura de artefactos líticos tuvieron lugar de manera recurrente y cotidiana en la misma cocina. Estas labores emplearon dos técnicas de talla distintas así como también la modificación de materiales líticos mediante el uso de artefactos no formatizados y litos no diferenciados.

De acuerdo con los datos recabados, la talla bipolar tuvo lugar en las primeras etapas de la secuencia de producción, dirigidas a la obtención de lascas, y su uso se restringió al cuarzo y la metacuarcita. La talla bipolar en el cuarzo permitiría obtener rápidamente lascas con biseles agudos en una materia prima de mala calidad para la talla directa. En cambio, la metacuarcita es una materia prima de buena calidad para la percusión directa, lo que nos ha llevado a formular dos hipótesis para investigaciones futuras, no excluyentes entre sí. Primero, que la talla bipolar permitió un aprovechamiento intensivo de esta roca (Andrefsky, 1998; Civalero, 2006; Flegenheimer et al., 1995), como podría indicar la presencia de una lasca de reactivación de núcleo de esta roca. La segunda alternativa es que la utilización de la técnica de talla bipolar se debió a la necesidad de reducir piezas muy pequeñas o muy difíciles de sostener para trabajar mediante percusión directa (Civalero, 2006). Ahora bien, la escasa cantidad de productos bipolares en la E1, su estado de fragmentación y la baja proporción de desechos indiferenciados en cuarzo y metacuarcita (Flegenheimer et al., 1995) permiten plantear que la aplicación de talla bipolar no habría sido muy recurrente dentro de E1. Los escasos productos bipolares registrados habrían sido obtenidos en otras estructuras de la casa, del sitio o en las fuentes, para ser utilizadas como formas base o lascas con filos naturales.

Por su parte, las técnicas de talla directa se emplearon principalmente en las últimas etapas de la secuencia de producción, dirigidas principalmente a la formatización y mantenimiento de artefactos formatizados y, en menor medida, en las etapas más tempranas de obtención de formas base a partir de núcleos.

La predominancia y recurrencia de actividades de formatización y mantenimiento de artefactos ya formatizados se habría dado en la mayoría de las materias primas, a juzgar por lo observado en el análisis tecnológico: el alto índice de lascas fracturadas y la baja representación de lascas enteras y fragmentos indiferenciados, la comparación de los tamaños y espesores entre los desechos de talla y los instrumentos, la predominancia de lascas anchas y cortas (relacionadas con la manufactura y mantenimiento de filos marginales, como los observados en la mayoría de los instrumentos), el predominio marcado de lascas internas y el bajísimo porcentaje general de corteza (Bernaldo de Quiros, Cabrera, Cacho y Vega, 1981; Fish, 1981; Prentiss, 2001; Sullivan y Rosen, 1985). Esta formatización de filos por talla directa habría ocurrido sobre formas base obtenidas en su extensa mayoría fuera de E1. Ahora bien, mientras algunos de los instrumentos 
formatizados en la cocina permanecieron y se emplearon allí (vide infra) en otros casos fueron retirados y se implicaron en actividades acontecidas en otros contextos, a juzgar por la presencia de desechos de talla de varias materias primas de las cuales no se han registrado instrumentos. Asimismo, es posible que los artefactos de mayor tamaño fueran retirados de la estructura en eventos de limpieza. Esta hipótesis requiere de profundización, sin embargo cabe pensar en la posibilidad de que estas actividades de limpieza hayan aportado a la generación de un conjunto artefactual conformado en gran parte por desechos y piezas de tamaños pequeños.

En el caso de algunas materias primas (andesitas An1, An2 y AnS, las dos variedades de basaltos, el cuarzo y la metacuarcita), los porcentajes de corteza y la presencia de lascas primarias y secundarias permiten suponer que al menos una pequeña parte del descortezamiento final de los materiales se realizaba en la propia cocina antes de las tareas de formatización.

Otra actividad recurrente habría sido el mantenimiento de instrumentos, según atestigua la gran cantidad de lascas de reactivación de filos recuperadas. Cabe mencionar que una parte de estas lascas de reactivación de filos son muy similares a las que diferentes autores definieron como lascas de mantenimiento de los cuchillos/ raederas de módulo grandísimo (Escola, Hocsman y Babot, 2013; Figura 6). Estas lascas particulares presentan tamaños pequeños, espesores delgados, módulos cortosanchos y en el sector proximal de la cara dorsal registran negativos de lascados que formaron parte del retoque del filo formatizado del artefacto al que pertenecieron. En la cara ventral suelen presentar un bulbo de tipo difuso y la presencia de labio. Los cuchillos/raederas de módulo grandísimo son artefactos recurrentes en los conjuntos líticos de sitios agropastoriles del NOA para momentos posteriores a los 2.000 años AP (Hocsman y Escola, 2006-2007).

Casi la totalidad de las lascas de reactivación de filos registradas en la E1 están confeccionadas sobre el basalto Bs1 al igual que todas las raederas (dos de las cuales son cuchillos/raederas de módulo grandísimo, Figura 6). El porcentaje de corteza presente entre estas lascas es más alto que en el resto de las categorías, lo cual se relaciona con el hecho de que los cuchillos/raederas de módulo grandísimo suelen confeccionarse por medio de retoque directo sobre lascas primarias o con una importante proporción de corteza en su cara dorsal, como sucede en los dos cuchillos/raederas de módulo grandísimo recuperados en el recinto (Figura 6).

Ahora bien, considerando que estos instrumentos implicaban mayores requerimientos que los demás artefactos formatizados tanto en el aprovisionamiento de la materia prima (lascas primarias, de gran tamaño y módulos particulares) como en su confección (filos largos y continuos, trabajos complementarios para eliminación de talón o rebaje de bulbo para enmangue), se entiende que haya existido una preocupación por prolongar su vida útil, siendo objeto de tareas de mantenimiento recurrentes dentro de la cocina de Cardonal. Por otro lado, la presencia de un núcleo de basalto Bs1, las proporciones de lascas externas y el registro de lascas de reactivación de núcleo en basalto Bs1, cuarzo y metacuarcita, indicarían que una pequeña parte de la talla directa habría estado dirigida a la obtención de lascas a partir de núcleos o al descortezamiento final de lascas para confeccionar artefactos, aunque se habría tratado de prácticas ocasionales y restringidas sólo a las rocas mencionadas.

\section{Cómo producir y mantener los utensilios}

La formatización y el mantenimiento de artefactos formatizados, aunque recurrentes en la cocina, no parecen haber involucrado grandes esfuerzos de tiempo, destreza u otros recursos tecnológicos. Los instrumentos se lograban por medio de la confección de 


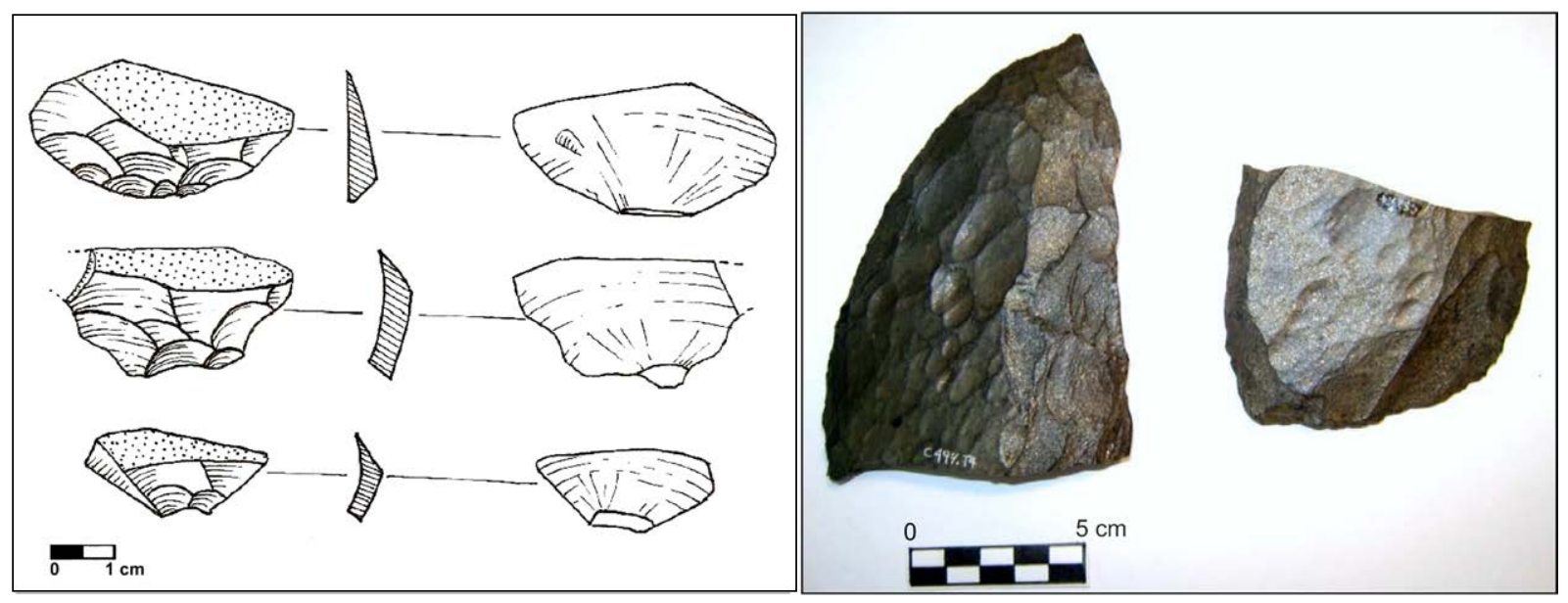

Figura 6. Izquierda: lascas de reactivación de cuchillos/raederas de módulo grandísimo halladas en la E1; derecha: cuchillos/raederas de módulo grandísimo recuperadas en la E1.

filos mayoritariamente unifaciales y marginales, y sólo en una muy pequeña proporción bifaciales, sobre biseles obtenidos al momento de extracción de las lascas.

En su gran mayoría, se trata de instrumentos simples, con un solo filo, punta o superficie activa, manufacturados a través de técnicas de retoque - sólo en pequeña medida precedidas por retalla-. Por su parte, la presencia de varios filos en los escasos instrumentos dobles y compuestos no habría involucrado una cantidad de esfuerzo extra considerable o mayor pericia técnica en comparación con los instrumentos simples. De hecho, es factible que la confección de nuevos filos sobre instrumentos ya formatizados estuviese aprovechando el trabajo ya invertido en ellos, presente en la forma de esos artefactos. Las excepciones están dadas por un par de filos bifaciales de arista sinuosa, en dos raederas pequeñas - a modo de dorsos, para facilitar la prensión- y en las dos raederas de módulo grandísimo cuyas porciones proximales han sido rebajadas - una sobre la cara ventral, quizás para eliminar el bulbo, la otra sobre la cara dorsal, para adelgazar el espesor en esa zona-. Dichos casos de inversiones de tiempo y esfuerzo tecnológico en la producción de esos artefactos podrían tender a facilitar su utilización, permitir la implementación de algún tipo de mango, para proteger la mano de quien utilice el artefacto, y a la vez mejorar el control de movimiento y reducir los requerimientos de fuerza durante su uso (Andrefsky, 1998; Tomka, 2001).

Teniendo en mente todo lo expuesto hasta ahora, es interesante observar las prácticas de producción lítica acontecidas en el recinto analizado en relación con lo que ocurría en el resto de las habitaciones de la casa (E2, E3, E4 y E5) (Videla, 2011). Si bien las actividades relacionadas con la producción lítica parecen haber tenido lugar en todas las habitaciones de la casa, se puede plantear que dentro de la cocina han sido mucho más recurrentes que en el resto de las habitaciones. Además, los resultados obtenidos por Cattáneo y Oliva (2008) en la E2 y por Videla (2011) en las E3 y E5 dan cuenta de actividades de producción lítica complementarias a las desarrolladas en E1. En el caso de la E2, la mayoría de las actividades del proceso de talla corresponderían al inicio del proceso de reducción, es decir, que quizás allí se habrían obtenido los soportes que fueron formatizados en la E1. Con respecto a las E3 y E5, Videla (2011) interpreta estos contextos como locaciones de actividades de taller de talla lítica en base a la cantidad de desechos de talla, instrumentos y núcleos recuperados. Aunque todavía no se cuenta con análisis de tipo tecnológico de los conjuntos líticos de estas estructuras, es factible que estudios futuros den cuenta de una variabilidad de instancias de producción lítica en las distintas habitaciones, con mayor recurrencia de las etapas más tempranas de 
la secuencia de producción, de reducción de núcleos y obtención de lascas, parte de las cuales luego habrían sido ingresadas a la cocina para tareas de formatización de instrumentos.

Entonces, las actividades de talla lítica desarrolladas en E1 y relacionadas con las últimas etapas del proceso de producción habrían hecho uso de productos obtenidos en el resto de las habitaciones de la casa para confeccionar instrumentos. Las herramientas de piedra de la cocina habrían tomado parte en prácticas recurrentes, cotidianas y de importancia para los habitantes de la casa, dentro de la red de las diversas actividades que conformaban la cotidianeidad de estas personas. Es probable que la cocina brindara un ambiente particular, generado por la presencia del fogón (Calo et al., 2012), alrededor del cual pudieron haber confluido una multiplicidad de personas vinculadas a la casa con diferentes tareas en diversos momentos: la cocción y consumo de alimentos, preparación de bebidas, producción y mantenimiento de objetos personales, de herramientas, de otras tecnofacturas, entre otras.

\section{El empleo del instrumental}

De acuerdo con la forma de los grupos tipológicos registrados en los artefactos es posible inferir una gama de modos de acción potenciales para ellos y, de esta forma, plantear qué tipo de actividades habrían estado habilitadas por el conjunto instrumental. Se parte de la premisa de que las formas de los filos, puntas o superficies de los instrumentos fueron modificadas - a través de la talla o de su utilización - para desempeñar alguna tarea particular, por lo cual esas formas están en relación con los gestos y modos de acción en que fueron utilizadas (Andrefsky, 1998; Aschero, 1983). En este sentido, proponemos una serie de "inferencias funcionales" (sensu Aschero, 1983) para ser manejadas a modo de hipótesis a ser corroboradas por investigaciones futuras.

De acuerdo con lo expuesto hasta ahora, los instrumentos líticos hallados en E1 intervinieron en dos esferas de acción: la subsistencia y el mantenimiento de la cocina y de la casa. Ambos grupos de prácticas debieron desarrollarse en diversos contextos y quizás implicaran la realización de distintos tipos de tareas por parte de diferentes grupos de personas.

\section{En las actividades de subsistencia}

Si se considera a la tecnología como un compromiso significativo de los actores sociales con sus condiciones materiales de existencia, en el cual ambas partes son creadas y recreadas en esa relación, las actividades de subsistencia ya no pueden ser entendidas como control de la naturaleza - o de sus características entendidas como recursossino como prácticas de vinculación de los agentes con su entorno natural y social, en las cuales las personas sustentan su existencia, su reproducción biológica y social, apropiándose y modificando las condiciones existentes y creando nuevas. Interesa resaltar dos tipos de instrumentos que, etnográfica y arqueológicamente, han sido relacionados con prácticas de subsistencia: las puntas de proyectil y las raederas de módulo grandísimo. Estos instrumentos se relacionan con contextos de utilización que están fuera de las habitaciones de la aldea de Cardonal y que se enmarcan en dos formas muy diferentes de resolver la subsistencia: los paisajes de caza y los campos de cultivo.

Por un lado, las puntas de proyectil son artefactos con una función especializada, conformando el elemento lítico de los sistemas de armas utilizadas en la cacería de animales silvestres (Andrefsky, 1998; Martínez, 1999). En este sentido, toman parte en actividades de tipo extractivas de obtención de recursos animales silvestres, los cuales, habrían sido un importante aporte a la dieta de los habitantes de la vivienda (Izeta, 
2007). Por otro lado, los cuchillos/raederas de módulo grandísimo se relacionan con el cultivo y el procesamiento de especies vegetales silvestres y domesticadas. Estos grandes instrumentos han sido asociados en contextos puneños con el manejo de vegetales, particularmente actividades de siega, corte y trilla de especies agrícolas (Escola et al., 2013).

En la cocina de Cardonal, se han registrado dos cuchillos/raederas de módulo grandísimo, ambos fracturados, por lo que quizás han sido ingresados aquí una vez excluidos de las labores agrícolas. Sin embargo, la gran cantidad de desechos de reactivación de estos artefactos permiten proponer que su ingreso a la cocina para tareas de mantenimiento era bastante recurrente, es decir, que estos instrumentos formaban parte de la cotidianeidad de ese contexto. Probablemente los cuchillos/ raederas confeccionados y/o mantenidos aquí hayan cumplido roles similares a los registrados en los contextos puneños, aunque no se puede descartar su empleo en la recolección de especies vegetales silvestres o incluso en el procesamiento de otros tipos de materiales.

\section{En el mantenimiento de la cocina y de la casa}

La mayoría de los instrumentos del conjunto presenta filos activos largos o no restringidos (raederas, cuchillos, cortantes, artefactos mediano-pequeños/muy pequeños con retoque en bisel oblicuo y artefactos de formatización sumaria) que pueden ajustarse a un rango relativamente amplio de modos de acción (Escola, 2000). Asimismo, instrumentos con varios filos diferentes implican la posibilidad de que hayan sido utilizados para una mayor diversidad de tareas. Por otro lado, algunos instrumentos presentan filos discretos, cuya morfología estaría indicando algún grado de especialización en sus potenciales modos de acción (artefactos burilantes, perforadores, denticulados, muescas y semimuescas).

El rango de modos de acción potencialmente habilitados por este conjunto involucra raspar, raer, cortar, perforar, grabar, etc. Parte de estas acciones pueden ser asociadas con el procesamiento y la cocción de alimentos: trozar animales, extraer cuero y tendones, cortar y picar vegetales, etc. Otras se habrían implicado en diversas manufacturas, como la confección y el mantenimiento de objetos cotidianos de la casa y/o personales: vestimenta, tecnofacturas en madera y/o hueso, cestería, cerámica, etc.

Mientras que la mayoría de los instrumentos analizados fueron formatizados para adecuar sus biseles o puntas a las diversas tareas, algunas de las actividades de mantenimiento de la cocina y de la casa hicieron uso de lascas de basalto Bs1, andesita An1 y cuarzo, así como también de lajas, guijarros y nódulos de rocas metamórficas foliadas, las que fueron utilizadas directamente, sin preparación de los biseles o puntas por medio de talla. El uso recurrente de estos soportes sin formatización está evidenciado por la modificación de sus superficies activas, ya sea en la forma de pulidos o superficies abradidas como por la presencia de rastros complementarios. Es decir, que estos materiales fueron conformados como instrumentos, no en el contexto de la fabricación de utensilios - como sucede en la mayoría de los instrumentos analizadossino por el uso repetido y recurrente de este instrumental. En general, su conformación morfológica habilita rangos de gestos similares a los artefactos formatizados.

\section{Conclusiones}

El análisis del material lítico hallado al interior de la cocina de Cardonal permitió reconstruir algunos aspectos de las diversas actividades cotidianas llevadas a cabo 
en esta aldea a comienzos de la era cristiana. Los habitantes de la casa emplearon una amplia variedad de rocas, que implicaron distintas vías para su obtención. Estos materiales y las prácticas en las que se involucraron remiten a lugares y personas ubicados a diversas distancias y direcciones de la casa de Cardonal. En el ámbito más cercano, la presencia de materias primas inmediatas y mediatas hace suponer el manejo de un paisaje local amplio, dentro del cual la apropiación de recursos naturales (agua, leña, pasturas, fuentes de materias primas) debió implicar relaciones de negociación con otras comunidades asentadas en la zona. Para el momento de ocupación de Cardonal hay varias aldeas contemporáneas, como Yutopián y Bordo Marcial (Scattolin et al., 2009a, 2009b). Estas y otras relaciones pueden haber permitido el acceso de tipo directo y recurrente a rocas locales pero más lejanas, como los basaltos.

Por otra parte, la presencia de materias primas no locales señala la existencia de interacciones sociales a una escala macroregional y conectan a la casa de Cardonal con paisajes y personas más distantes, implicadas en redes de interacción que seguramente involucraban otros objetos, así como también conocimientos y recursos estilísticos y técnicos. En relación con esto, la morfología de los cuchillos/raederas de módulo grandísimo remiten a la existencia de un conjunto de información técnica que era compartida entre varios contextos del noroeste argentino posteriores a los 2.000 años AP (Escola et al., 2013).

En cuanto al marco específico de la cocina de Cardonal, en su interior se manufacturó una amplia variedad de instrumentos como así también se cuidó y renovó instrumental particular como los cuchillos/raederas de módulo grandísimo. El conjunto instrumental habilita un amplio espectro de modos de acción que se desarrollan en el marco de la subsistencia, la cacería, las labores agrícolas, y diversas tareas cotidianas de mantenimiento de la cocina y de la casa: procesamiento y consumo de alimentos, producción de tecnofacturas cerámicas, óseas, etc. Así, el estudio del material lítico permitió expandir la reconstrucción de la vida práctica de una vivienda de Cardonal, en tanto espacio multifuncional donde confluyeron diferentes personas, que cumplían distintos roles y traían a la cocina y a la vida cotidiana elementos de contextos diversos y distantes, en suma, construyendo con ellos su mundo.

\section{Agradecimientos}

Las excavaciones en Cardonal fueron sostenidas con fondos de proyectos PICT de la Agencia Nacional de Promoción Científica y Tecnológica o 00-09575, ํo04-20194, RAÍCES/PICT No 00116, PIP de CONICET 6553 y subsidios de la UNLP N11-561. Agradecemos las oportunas recomendaciones de los revisores anónimos. 


\section{Referencias citadas}

" Andrefsky, W. Jr. (1998). Lithics. Macroscopic approaches to analysis. Cambridge: Cambridge University Press.

》 Aschero, C. A. (1975). Ensayo para una clasificación morfológica de artefactos líticos aplicada a estudios tipológicos comparativos. Informe al CONICET. Manuscrito inédito.

》 Aschero, C. A. (1983). Ensayo para una clasificación morfológica de artefactos líticos. Cátedra de Ergología y Tecnología, Facultad de Filosofía y Letras, Universidad de Buenos Aires. Manuscrito inédito.

» Aschero, C. A. y Hocsman, S. (2004). Revisando cuestiones tipológicas en torno a la clasificación de artefactos bifaciales. En M. Ramos, A. Acosta y D. Loponte (Comps.), Temas de Arqueología. Análisis Lítico (pp.7-25). Luján: Universidad Nacional de Luján.

" Baqueiro Vidal, S. (2006). La producción lítica del yacimiento neolítico de O Regueiriño (Moaña, Pontevedra). Cuadernos de Estudios Gallegos, 119, 55-85.

» Bellelli, C., Guráieb, G. y García, J. (1985-87). Propuesta para el análisis y procesamiento por computadora de desechos de talla lítica (DELCO-Desechos Líticos Computarizados). Arqueología Contemporánea, 2(1), 36-53.

" Bernaldo De Quirós, F., Cabrera, V., Cacho, C. y Vega, L. G. (1981). Proyecto de análisis técnico para las industrias líticas. Trabajos de Prehistoria, 38, 9-37.

》 Binford, L. R. (1979). Organization and formation processes: looking at curated technologies. Journal of Anthropological Research, 35, 255-273.

" Bourdieu, P. (1980). El sentido práctico. Buenos Aires: Siglo XXI Editores.

» Bugliani, M. F., Calo, C. M. y Scattolin, M. C. (2010) Fumando en la cocina. Determinación de contenidos por técnicas fisicoquímicas en dos pipas cerámicas del sitio Cardonal. En Bertolino, S., Cattáneo, R. y lzeta, A. D. (Eds.), La arqueometría en Argentina y Latinoamérica (pp. 231-236). Córdoba: Editorial de la Facultad de Filosofía y Humanidades, Universidad Nacional de Córdoba.

》 Calo, C. M. (2010). Plantas útiles y prácticas económicas entre los aldeanos al sur de los Valles Calchaquíes. (Tesis doctoral inédita), Universidad Nacional de La Plata, Argentina.

" Calo, C. M., Bugliani, M. F. y Scattolin, M. C. (2012). Allí algo se cocina. Espacios de preparación de alimentos en el valle del Cajón. En P. Babot, M. Marschoff y F. Pazzarelli (Eds.), Las manos en la masa: arqueologías, antropologías e historias de la alimentación en Suramérica (pp. 443-461). Córdoba y Tucumán: Museo de Antropología, Facultad de Filosofía y Humanidades, Universidad de Córdoba - Instituto Superior de Estudios Sociales Universidad Nacional de Tucumán.

»Cattáneo, G. R. y Oliva Bustamante, A. V. (2008). Informe de análisis de desechos de talla: Sitio cardonal. Núcleo 1. Estructura 2. Campaña 2004. Manuscrito inédito.

"Civalero, M. T. (2006). De roca están hechos: Introducción a los análisis líticos. En C. Pérez de Micou (Ed.), El modo de hacer las cosas. Artefactos y ecofactos en arqueología (pp. 35-65). Buenos Aires: Facultad de Filosofía y Letras, Universidad de Buenos Aires.

" Dobres, M. A. (1999). Technology's links and chaînes: the processual unfolding of technique and technician. En M. A. Dobres y C. R. Hoffman (Eds.), The social dynamics of technology. Practice, politics and world views (pp. 124-146). Washington: Smithsonian Institution Press. 
"Escola, P. S. (2000). Tecnología lítica y sociedades agro-pastoriles tempranas. (Tesis Doctoral inédita), Universidad de Buenos Aires, Argentina.

»Escola, P. S., Hocsman, S. y Babot, M. P. (2013). Entre las residencias y los campos de cultivo. Aportes de los cuchillos/raederas de módulo grandísimo a la cuestión del laboreo agrícola en Antofagasta de la Sierra (Puna de Catamarca) durante el primer milenio D.C. Relaciones de la Sociedad Argentina de Antropología, XXXVIII(1), 83-110.

» Fábregas Valcarce, R. y Rodríguez Rellán, C. (2008). Gestión del cuarzo y la pizarra en el Calcolítico peninsular: el "santuario" de El Pedroso (Trabazos de Aliste, Zamora). Trabajos de Prehistoria, 65(1), 125-142.

" Fish, P. R. (1981). Beyond tools: middle paleolithic debitage analysis and cultural inference. Journal of Anthropological Research, 37, 374-386.

" Flegenheimer, N., Bayón, C. y González De Bonaveri, M. I. (1995). Técnica simple, comportamientos complejos: la talla bipolar en la arqueología bonaerense. Relaciones de la Sociedad Argentina de Antropología, XX, 81-110.

" Gero, J. M. (2015). Yutopian. Archaeology, ambiguity and the production of knowledge in Northwest Argentina. Austin: University of Texas Press.

» Hocsman, S. y Escola, P. S. (2006-2007). Inversión de trabajo y diseño en contextos líticos agro-pastoriles (Antofagasta de la Sierra, Catamarca) Cuadernos del Instituto Nacional de Antropología y Pensamiento Latinoamericano, 21, 75-90.

" Ingold, T. (1990). Society, nature and the concept of technology. Archaeological Review from Cambridge, 9(1), 5-17.

»Ingold, T. (2000). Making culture and weaving the world. En P. M. Graves-Brown (Ed.), Matter, Materiality and Modern World (pp. 50-71). Londres: Routledge.

»Izeta, A. D. (2007). Zooarqueología del Formativo del valle del Cajón. Simposio 9: de la Puna a las Sierras: Avances y perspectivas en Zooarqueología. Pacarina. Actas del XVI Congreso Nacional de Arqueología Argentina, Tomo I, 471-476.

"Lazzari, M., Pereyra Domingorena, L., Scattolin, M. C., Cecil, L., Glascock, M. D. y Speakman, R. J. (2009). Ancient social landscapes of northwestern Argentina: preliminary results of an integrated approach to obsidian and ceramic provenance. Journal of Archaeological Science, 36, 1955-1964.

" Martínez, J. (1999). Puntas de proyectil: diseños y materias primas. En C. Aschero, A. Korstanje y P. Vuoto (Eds.), En los tres reinos. Prácticas de recolección en el Cono Sur de América (pp. 61-69). Tucumán: Ediciones Magna.

»Meltzer, D. J. (1989). Was stone exchanged among eastern North American paleoindians? En C. J. Ellis (Ed.), Eastern Paleoindian Lithic Resource Use (pp. 11-39). Boulder: Westview Press.

»Moreno, E. A. y Sentinelli, N. (2014). Tecnología lítica en las tierras altas de Ancasti. Cuadernos de la Facultad de Humanidades y Ciencias Sociales (UNJu), 45, 95-115.

"Pfaffenberger, B. (1992). Social Anthropology of Technology. Annual Review of Anthropology, 21, 491-516.

»Pfaffenberger, B. (1999). Worlds in the Making: Technological Activities and the Construction of Intersubjective Meaning. En M. Dobres y C. Hoffman (Eds.), The Social Dinamics of Technology. Practice, Politics and World Views (pp. 147-165). Washington: Smithsonian Institution Press.

》Prentiss, W. C. (2001). Reliability and validity of a "Distinctive assemblage" tipology: integrating flake size and completeness. En W. Andrefsky Jr. (Ed.), Lithic debitage. Context. Form. Meaning (pp. 147-172). Utah: The University of Utah Press. 
» Scattolin, M. C., Bugliani, M. F., Cortés, L. I., Calo, C. M., Pereyra Domingorena, L. e Izeta, A. D. (2009a). Pequeños mundos: Hábitat, maneras de hacer y afinidades en aldeas del valle del Cajón, Catamarca. Relaciones de la Sociedad Argentina de Antropología, XXXIV, 251-274.

» Scattolin, M. C., Cortés, L. I., Bugliani, M. F., Calo, C. M., Pereyra Domingorena, L., Izeta, A. D. y Lazzari, M. (2009b). Built landscapes of everyday life: a house in an early agricultural village of northwestern Argentina. World Archaeology, 41(3), 396-414.

»Sentinelli, N. (2012). Tecnología lítica en una 'cocina' del Valle del Cajón (Dpto. Santa María, Pcia. de Catamarca). Una perspectiva microescalar. (Tesis de Licenciatura inédita), Universidad Nacional de Catamarca, Argentina.

»Sentinelli, N. (2016). Prácticas tecnológicas y materias primas líticas en un contexto doméstico del Valle del Cajón (Santa María, Catamarca). Cuadernos de la Facultad de Humanidades y Ciencias Sociales (UNJu), 49, 175-197.

»Sentinelli, N. y Toselli, G. (2013). Identificación macroscópica y microscópica de materias primas líticas en Cardonal (Valle del Cajón, Catamarca, Argentina). Una primera aproximación a su aprovechamiento. La Zaranda de Ideas. Revista de Jóvenes Investigadores en Arqueología, 9(2), 119-137.

»Sullivan III, A. y Rozen, K. (1985). Debitage analysis and archaeological interpretation. American Antiquity, 50(4), 755-779.

» Tomka, S. A. (2001). The effect of procesing requirements on reduction strategies and tool form: a new perspective. En W. Andrefsky Jr. (Ed.), Lithic debitage. Context. Form. Meaning (pp. 207-224). Utah: The University of Utah Press.

» Tringham, R. E. (1999). Casas con caras: el reto del género en los restos arquitectónicos prehistóricos En L. Colomer, P. González Marcén, S. Montón y M. Picazo (Eds.) Arqueología y teoría feminista. Estudios sobre mujeres y cultura material (pp. 173-214). Barcelona: Editorial Icaria.

»Videla, M. V. (2011). Distribución y consumo de materiales líticos tallados en una vivienda del Período Formativo del Valle del Cajón, Catamarca. En A. D. Calisaya, V. Erramouspe y V. B. Silva (Comps.), Arqueogasta. Estudiando el pasado... repensando el futuro (pp. 82-84). Tucumán: Universidad Nacional de Tucumán. 